Chemical Technology

Division

Chemical Technology

Division

Chemical Technology

Division

Chemical Technology

Division

Chemical Technology

Division

Chemical Technology

Division

Chemical Technology

Division

Chemical Technology

Division

Chemical Technology

Division

Chemical Technology

Division

Chemical Technology

Division

Chemical Technology

Division

Chemical Technology

Division

Chemical Technology

Division

Chemical Technology

Division

Chemical Technology

\title{
Actinide Recovery Using Aqueous Biphasic Extraction: Initial Developmental Studies
}

by D. J. Chaiko, R. Mensah-Biney, C. J. Mertz, and A. N. Rollins

Division

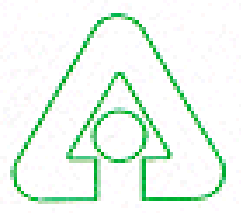

Argonne National Laboratory, Argonne, Illinois 60439

operated by The University of Chicago

for the United States Department of Energy under Contract W-31-109-Eng-38

Chemical Technology

Division

Chemical Technology

Division

Chemical Technology Reseived by asth

Division

Chemical Technology

NoV 021992 
Argonne National Laboratory, with facilities in the states of Illinois and Idaho, is owned by the United States government, and operated by The University of Chicago under the provisions of a contract with the Department of Energy.

\section{DISCLAIMER}

This report was prepared as an account of work sponsored by an agency of the United States Government. Neither the United States Government nor any agency thereof, nor any of their employees, makes any warranty, express or implicd, or assumes any legal liability or responsibility for the accuracy, completeness, or usefulness of any information, apparatus, product, or process disclosed, or represents that its use would not infringe privately owned rights. Reference herein to any specific conmercial product, process, or service by trade name, trademark, manufacturer, or otherwise, does not necessarily constitute or imply its endorsement, recommendation, or favoring by the United States Govemment or any agency thereof. The views and opinions of authors expressed herein do not necessarily state or reflect those of the United States Government or any agency thereof.

Reproduced from the best available copy.

Available to DOE and DOE contractors from the

Office of Scientific and Technical Information P.O. Box 62

Oak Ridge, TN 37831

Prices available from (615) 576-8401

Available to the public from the National Technical Information Service

U.S. Department of Commerce

5285 Port Royal Road

Springfield, VA 22161 


\title{
ACTINIDE RECOVERY USING AGUEOUS BIPHASIC EXTRACTION: INITIAL DEVELOPMENTAL STUDIES
}

\author{
by
}

D. J. Chaiko, R. Mensah-Biney,

C. J. Mertz, and A. N. Rollins

Hazardous Waste Program

Chemical Technology Division

August 1992

\section{MASTER}

DISTRIBUTION OF THIS OOCUMENT IS UNLIMITED 



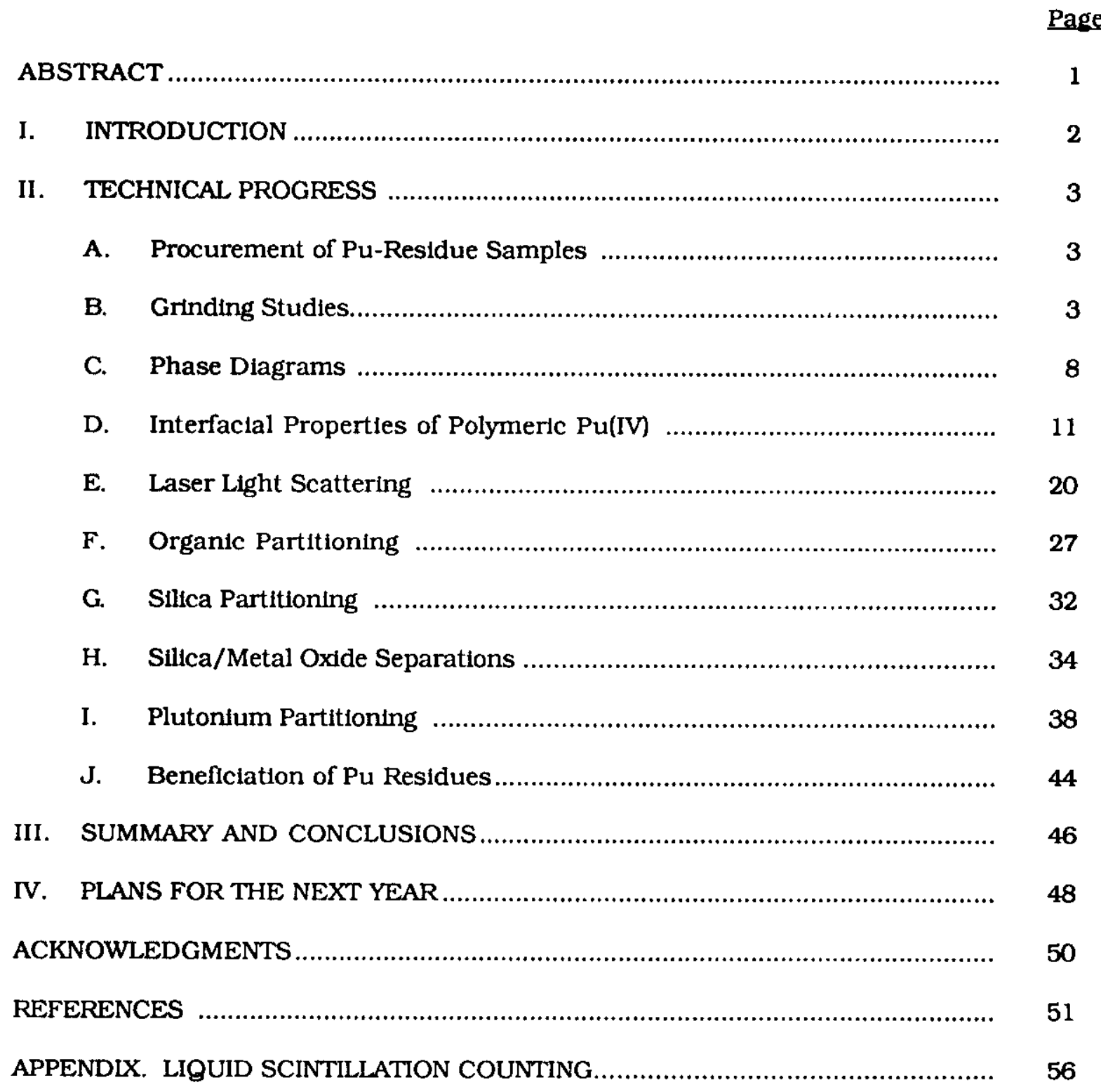




\section{LIST OF FIGURES}

No.

$\underline{\text { Title }}$

Page

1. Cumulative Particle Size Distributions Measured by Light Scattering for

Ground LECO Crucible and $\mathrm{Al}_{2} \mathrm{O}_{3}$

2. Phase Diagram for the PEG-10,000/Sodium Sulfate

System at $25^{\circ}$ and $80^{\circ} \mathrm{C}$

3. Phase Diagram of the PEG/Sodium Sulfate System at $25^{\circ} \mathrm{C}$

4. Adsorption of Polymeric Pu(IV) onto Glass from

7.5 wt \% Sulfuric and Nitric Acid Solutions at $25^{\circ} \mathrm{C}$

5. Adsorption of Polymertc Pu(IV) onto Glass from 7.5 wt \% Sodium

Sulfate and Sodium Nitrate Solutions at $22^{\circ} \mathrm{C}$

6. Adsorption of Polymeric Pu(IV) onto Glass and Polyethylene

from $7.5 \mathrm{wt} \%$ Sodium Sulfate Solutions at $22^{\circ} \mathrm{C}$

7. Adsorption of Polymeric Pu(IV) onto Successtve Glass Vials

From 7.5 wt \% Sodium Sulfate at $22^{\circ} \mathrm{C}$

8. Langmiur Plot for Colloidal Pu(IV) Adsorption onto Glass .

9. Effect of AOT and Dextran on the Adsorption of Polymeric Pu(IV)

onto Glass from $7.5 \mathrm{wt} \%$ Sodium Sulfate Solutions at $22^{\circ} \mathrm{C}$

10. Effect of Additives on the Adsorption of Polymeric Pu(IV) onto

Polyethylene from $7.5 \mathrm{wt} \%$ Sodium Sulfate at $22^{\circ} \mathrm{C}$

11. Schematic Diagram of Cell Holders for $1-\mathrm{mL}, 7-\mathrm{mL}$, and 20-mL Sample Cells.

12. Plot of Net Autocorrelation Function for BSA at $25^{\circ} \mathrm{C}$

13. Plot of Net Autocorrelation Function for Cytochrome c at $25^{\circ} \mathrm{C}$

14. Plot of Net Autocorrelation Function for Pu-polymer at $25^{\circ} \mathrm{C}$

15. Structural Formulas of Water-Soluble Complexants

16. Extraction of Polymeric Pu(IV) by Arsenazo III in the $15 \%$

$\left(\mathrm{NH}_{4}\right)_{2} \mathrm{SO}_{4} / 15 \%$ PEG-3400 System at a pH of 6 and $25^{\circ} \mathrm{C}$ 


\section{LIST OF FIGURES (contd.)}

№.

Title

Page

17. Extraction of Polymeric Pu(IV) by Arsenazo III as a Function of $\mathrm{pH}$ in the $15 \%\left(\mathrm{NH}_{4}\right)_{2} \mathrm{SO}_{4} / 15 \%$ PEG-3400 System at $25^{\circ} \mathrm{C}$

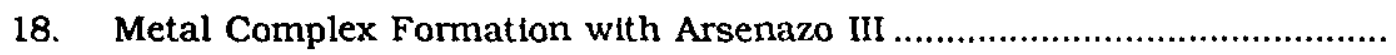




\section{LIST OF TABLES}

№.

Title

Page

1. Effect of Grinding Time on Product Size for Several Materlals................. 4

2. Product Size Obtained with Agate Grinding Media .................................. 5

3. Partition Coefficients for Several Water Soluble Metal Complexants......... 29

4. Surface-Modifled Phase Transfer in Aqueous Blphasic Extraction ............ 35

5. Partition Coefficients and Corresponding Heats of Immersion in Water in the Sodium Sulfate/PEG System at a pH of 3

6. Partitioning of Monomeric and Polymeric Pu(IV) in the $7.5 \% \mathrm{Na}_{2} \mathrm{SO}_{4} /$ $15 \%$ PEG-3400 Blphase System at $25^{\circ} \mathrm{C}$

7. Partitioning of Polymeric Pu(IV) in the $15 \%\left(\mathrm{NH}_{4}\right)_{2} \mathrm{SO}_{4} /$ $15 \%$ PEG-3400 Blphase System at $25^{\circ} \mathrm{C}$

8. Plutonium Bulk Phase Recovery and Mass Balance during Extraction in the $15 \%\left(\mathrm{NH}_{4}\right)_{2} \mathrm{SO}_{4} / 15 \%$ PEG-3400 Biphase System at $25^{\circ} \mathrm{C}$.

9. Partitioning of Polymeric Pu(IV) in the $7.5 \% \mathrm{Na}_{2} \mathrm{SO}_{4} / 15 \%$ PEG-3400 System with $0.01 \%$ PTA Concentration at $25^{\circ} \mathrm{C}$

10. Partitioning of Polymeric Pu(IV) in the $7.5 \% \mathrm{Na}_{2} \mathrm{SO}_{4} / 15 \%$ PEG-3400 System with $0.1 \%$ PTA Concentration at $25^{\circ} \mathrm{C}$.

11. Partitioning of Colloidal $\mathrm{PuO}_{2}$ in Binary Particulate Systems................. 45

12. Effect of Arsenazo III Plutonlum Scintlllation Counting....................... 56

13. Effect of $\left(\mathrm{NH}_{4}\right)_{2} \mathrm{SO}_{4}$ on Plutonium Scintllation Counting ........................ 57 


\title{
ACTINIDE RECOVERY USING AGUEOUS BIPHASIC EXTRACTION: INITLAL DEVELOPMENTAL STUDIES
}

by

D. J. Chalko, R. Mensah-Biney, C. J. Mertz, and A. N. Rollins

\begin{abstract}
Aqueous biphasic extraction systems are being developed to treat radioactive wastes. The separation technique involves the selective partitioning of either solutes or colloid-size particles between two immiscible aqueous phases. Wet grinding of plutonium residues to an average particle size of one micron will be used to liberate the plutonium from the bulk of the particle matrix. The goal is to produce a plutonium concentrate that will integrate with existing and developing chemical recovery processes. Ideally, the process would produce a nonTRU waste stream. Coupling physical beneficiation with chemical processing will result in a substantial reduction in the volume of mixed wastes generated from dissolution recovery processes.
\end{abstract}

As part of this program, we will also explore applications of aqueous biphasic extraction that include the separation and recovery of dissolved specles such as metal ions and water-soluble organics.

The expertise and data generated in this work will form the basis for developing more cost-effective processes for handling waste streams from environmental restoration and waste management activities within the DOE community.

This report summarizes the experimental results obtained during the first year of this effort. Experimental efforts were focused on elucidating the surface and solution chemistry varlables which govern partitioning behavior of plutonium and silica in aqueous biphasic extraction systems. Additional efforts were directed toward the development of wet grinding methods for producing ultrafine particles with diameters of one micron or less. 


\section{INTRODUCTION}

Current beneficiation strategies for plutonium residues include the incineration of combustibles, such as wood, paper, plastics, and olls; particle-size reduction where necessary; and washing, leaching, or dissolution with acid. The pregnant solutions are then further processed to yield either $\mathrm{PuO}_{2}$ or $\mathrm{PuF}_{4}$. Metal oxides (both reactive and high-fired) and impure plutonium metal are processed by elther direct oxide reduction, molten salt extraction, or electrorefining [CHRISTENSEN].

Historically, both hydrometallurgical and pyrometallurgical processing of plutonium residues have been carried out with little or no physical beneficiation prior to chemical processing. Notable exceptions include the recent attempts to use magnetic separation techniques to produce a uranium concentrate from magnesium fluoride [HOEGLER, WICHNER] and plutonlum concentrates from various pyrochemical residues [AVENS].

Many of the plutonlum residues generated during fuel reprocessing and plutonium recovery operations are heterogeneous materials, with the plutonium being distributed as discrete grains within a larger particle matrix. Some examples include pyrochemical residues, such as sand, slag, and crucibles; graphite; and chloride salts. Ultrafine grinding to an average particle size of about one micron can be expected to liberate the plutonium from the particle matrix. Selective partitioning in an aqueous biphasic extraction process could then produce a plutonium concentrate.

Aqueous biphase systems were originally developed by Albertsson in the mid1950s for the separation of microbial cells, cell organelles, and viruses [ALBERTSSON]. In recent years, interest in aqueous biphasic systems has broadened to include applications in commercial-scale protein separations [KULA, WALTER], separation of metal Ions [ZVAROVA - 1984A, ZVAROVA-1984B, MOLOCHNIKOVA-1988A. MOLOCHNIKOVA-1988B], ultrafine particles [ANANTHAPADMANABHAN-1987A], and organics [GULLICKSON, CHAIKO-1989]. Aqueous biphasic extraction involves the selective partitioning of either solutes or colloidal-size particles between two immiscible aqueous phases. These aqueous/aqueous systems form spontaneously from mixtures of aqueous solutions of unlike polymers, typically a straight-chain polymer such as polyethylene glycol (PEG) and a highly branched polymer such as dextran. Aqueous/aqueous systems may also be generated from mixtures of polymer and inorganic salt solutions. For example, combining equal volumes of a 15 -wt \% solution of sodium sulfate and a $30-w t \%$ solution of $\mathrm{PEG}-\mathbf{3 4 0 0}$ produces a turbid mixture that will separate after a few minutes, with the sodium sulfate concentrated in the bottom layer and the polymer concentrated in the top layer.

Aqueous biphase systems behave similarly to conventional solvent extraction systems, but because they do not utilize an organic diluent, which may itself become a source of pollution, they are particularly attractive for waste treatment applications. In addition, the water-soluble polymers that have been used in biphase formation are inexpensive, nontoxic, and biodegradable. They can also be removed from the process effluents for recycle by ultrafiltration [GULLICKSON] or electrodialysis [HUSTEDT]. Alternatively, suspended solids can be removed by high-speed centrifugation [ALBERTSSON], allowing the aqueous phases to be recycled. 
The objectives of this study are (1) to verify the technical feasibility of using aqueous biphasic extraction in treating plutonium-containing residues, (2) to identify the most likely residue candidates for biphasic extraction based on treatability and economic criteria, and (3) to further develop the technology to provide a proof-ofconcept for the selective recovery of actinides from complex, particulate materials. The work required to meet these goals will be carried out over a three-year period. This report describes the experimental results obtained during the first year of this effort.

\section{TECHNICAL PROGRESS}

\section{A. Procurement of Pu-Residue Samples}

An important part of this project involves screening several of the major Puresidues for potential applicability to aqueous biphasic extraction. To be amenable to this or any other physical beneficiation technique, the particulate feed materials must be heterogeneous and must respond favorably to grinding as a means of liberating the actinides from the gangue. Particle structure and liberation behavior are characteristics that can not be simulated using model systems. For this reason, we feel that it is imperative to use actual Pu-residue samples in the grinding and particle separation studies. A number of low-level Pu residues have been identifled as particularly attractive candidates for aqueous biphasic extraction studies. They include incinerator ash, ash heels, graphite, sand, slag, and crucible (SS\&C), and LECO crucibles. Altogether, these materlals represent a major portion of the bulk volume of the residue inventory and contain over half of the total plutonium in the residue inventory.

We currently plan to examine (1) LECO crucibles from Savannah River Lab, (2) calcined and blended ash heels from Rocky Flats Plant that were obtained through Lawrence Livermore Lab, (3) Incinerator ash obtained from Los Alamos, (4) plutonium contaminated graphite powder from Los Alamos, and (5) SS\&C from Westinghouse Hanford Co. We already have the first three samples and expect the last two shortly.

\section{B. Grinding Studies}

The purpose of comminution is to liberate the actinide species from the particle matrix and gangue so that physical separation and recovery of the actinides can be achieved. The degree of liberation is defined as the percentage of the valuable constituent occurring as free particles relative to the total quantity of material present. To liberate the actinides, the particle size must be less than the grain stze. Preliminary examinations of ash heel and LECO cructbles have shown that the plutonium is present as discrete 1- $\mu \mathrm{m}$ grains in the particle matrix [CHAIKO-1991A]

Initial grinding studies were carried out using several different materials of varying hardness, which included $\mathrm{SiO}_{2}, \mathrm{TiO}_{2}, \mathrm{CaCO}_{3}, \mathrm{Fe}_{2} \mathrm{O}_{3}, \mathrm{Al}_{2} \mathrm{O}_{3}$, high-fired $\mathrm{UO}_{2}$, and a LECO crucible. The initial grinding tests were conducted with nonradioactive materials in order to define procedures and grinding conditions appropriate for glovebox operations. 
The batch grinding tests were performed wet with a McCrone Micronising Mill (McCrone Research Associates, England). This vibratory mill can reduce the size of particles from $500 \mu \mathrm{m}$ to $1 \mu \mathrm{m}$ or less. The grinding jar is made of impact-resistant plastic and has a screw cap that provides a water-tight seal. The mill is designed to handle a maxium of 2 to $10 \mathrm{~g}$ of dry powder in a total slurry volume of $10 \mathrm{~mL}$. During all of the grinding tests, the mill feed consisted of $0.1 \mathrm{~g}$ dry powder plus $5.0 \mathrm{~mL}$ of delonized water and $0.1 \mathrm{wt} \%$ sodium hexametaphosphate as a dispersing agent.

We have investigated the effect of grinding time on the product size using times of $20 \mathrm{~min}$ to $15 \mathrm{~h}$. The particle size distributions of the products were measured by dynamic laser light scattering using a Malvern $4700 \mathrm{c}$ photon correlation spectrophotometer (Malvern Instruments, Southborough, MA). The system was fitted with a $35 \mathrm{~mW}$ HeNe laser and was mounted on an optical table (Technical Manufacturing Corp., Peabody, MA) having an overhead enclosure. Details of this system are provided in Section $\mathrm{E}$.

Titanium oxide has been studied extensively during these preliminary tests, but other metal oxides including iron oxide, aluminum oxide, silica, and calcium carbonate have also been included in the grinding tests. Table 1 lists the results of the grinding studies showing the average product size.

Table 1. Effect of Grinding Time on Product Size for Several Materials

\begin{tabular}{lccc}
\hline Feed Material & $\begin{array}{c}\text { Top Feed Size, } \\
\mu \mathrm{m}\end{array}$ & $\begin{array}{c}\text { Grinding Time, } \\
\mathrm{h}\end{array}$ & $\begin{array}{c}\text { Average Product Size, } \\
\mu \mathrm{m}\end{array}$ \\
\hline $\mathrm{TiO}_{2}$ & 44 & 1 & $\sim 2$ \\
& & 2 & 0.5 \\
$\mathrm{CaCO}_{3}$ & 10 & 6 & 0.5 \\
Silica & 200 & 4 & $\sim 2$ \\
& & 2 & $\sim 5$ \\
LECO crucible & 147 & 4 & 1.5 \\
& & 2 & $\sim 5$ \\
High-fired $\mathrm{UO}_{2}$ & 200 & 5 & $\sim 2$ \\
\hline
\end{tabular}


The results in Table 1 show that, with the exception of $\mathrm{TiO}_{2}$ and $\mathrm{UO}_{2}$, an average product size of $1 \mu \mathrm{m}$ or less was not achieved with any of the materials tested. These initial studies used corundum grinding media consisting of cylindrical elements that produce line contact blows and planar contact shears. We found that prolonged grinding times cause excessive wear of the corundum elements. This would account for the coarser-than-expected size distrlbution of the ground products $(>2.0 \mu \mathrm{m})$ and for the product size not changing significantly by varying the grinding time or the hardness of the feed material.

We found that the extent of grinding medium wear amounted to about $40.0 \mathrm{~g}$ out of the total initial medium weight of $275 \mathrm{~g}$. Based on the weight of material ground in the mill during this period, we estimate that the average medium wear amounted to approximately $2 \mathrm{~g}$ per four hours of grinding. This was confirmed by a test grind in which a mass balance of the solids showed that the ground product could become contaminated with as much as 20 times its weight by corundum $\left(\mathrm{Al}_{2} \mathrm{O}_{3}\right)$. Consequently, the ground products would be expected to exhibit the characteristics of corundum. rather than the particular metal oxide under study. In addition, the net effect of media wear is to provide a continueous supply of particles that are in excess of 1 micron in diameter.

In an attempt to reduce the sample contamination by the grinding media, we switched from corundum to agate grinding elements, which are harder. In addition, the mill feed was increased from $0.10 \mathrm{~g}$ to $0.50 \mathrm{~g}$ or more to decrease the amount of elementto-element contact. With these changes, we were able to reduce the grinding time and still obtain a submicron-stzed product. The particle size distributions were then measured using both light scattering and the Andreasen pipet. The size data in Table 2 were obtained with the Andreasen pipet. Since this method is based on gravitational sedimentation, it is not practical to measure particle sizes below $0.5 \mu \mathrm{m}$. Therefore, the results of the sedimentation measurements shown in Table 2 were limited to particle sizes greater than $0.5 \mu \mathrm{m}$. Light scattering data are shown in Fig. 1.

Table 2. Product Size Obtained with Agate Grinding Media ${ }^{a}$

\begin{tabular}{|c|c|c|c|c|}
\hline \multirow{2}{*}{$\begin{array}{l}\text { Feed } \\
\text { Material }\end{array}$} & \multirow{2}{*}{$\begin{array}{l}\text { Top Feed } \\
\text { size, } \mu \mathrm{m}\end{array}$} & \multirow{2}{*}{$\begin{array}{l}\text { Grinding } \\
\text { Time, hr. }\end{array}$} & \multicolumn{2}{|c|}{ Product Size wt \% } \\
\hline & & & $<1.0 \mu \mathrm{m}$ & $1-2 \mu \mathrm{m}$ \\
\hline $\mathrm{TiO}_{2}$ & 44 & 4.0 & 94 & 6 \\
\hline Glass $\left(\mathrm{SiO}_{2}\right)$ & $3-10$ & 4.0 & 93 & 7 \\
\hline $\mathrm{Fe}_{2} \mathrm{O}_{3}$ & 44 & $\begin{array}{l}2.0 \\
4.0\end{array}$ & $\begin{array}{l}42 \\
75\end{array}$ & $\begin{array}{c}32 \\
7\end{array}$ \\
\hline LECO crucible & 147 & 6.0 & 98 & 2 \\
\hline $\mathrm{Al}_{2} \mathrm{O}_{3}$ & 44 & 4.0 & 82 & 8 \\
\hline
\end{tabular}

aproduct size data obtained with Andreasen pipet. 


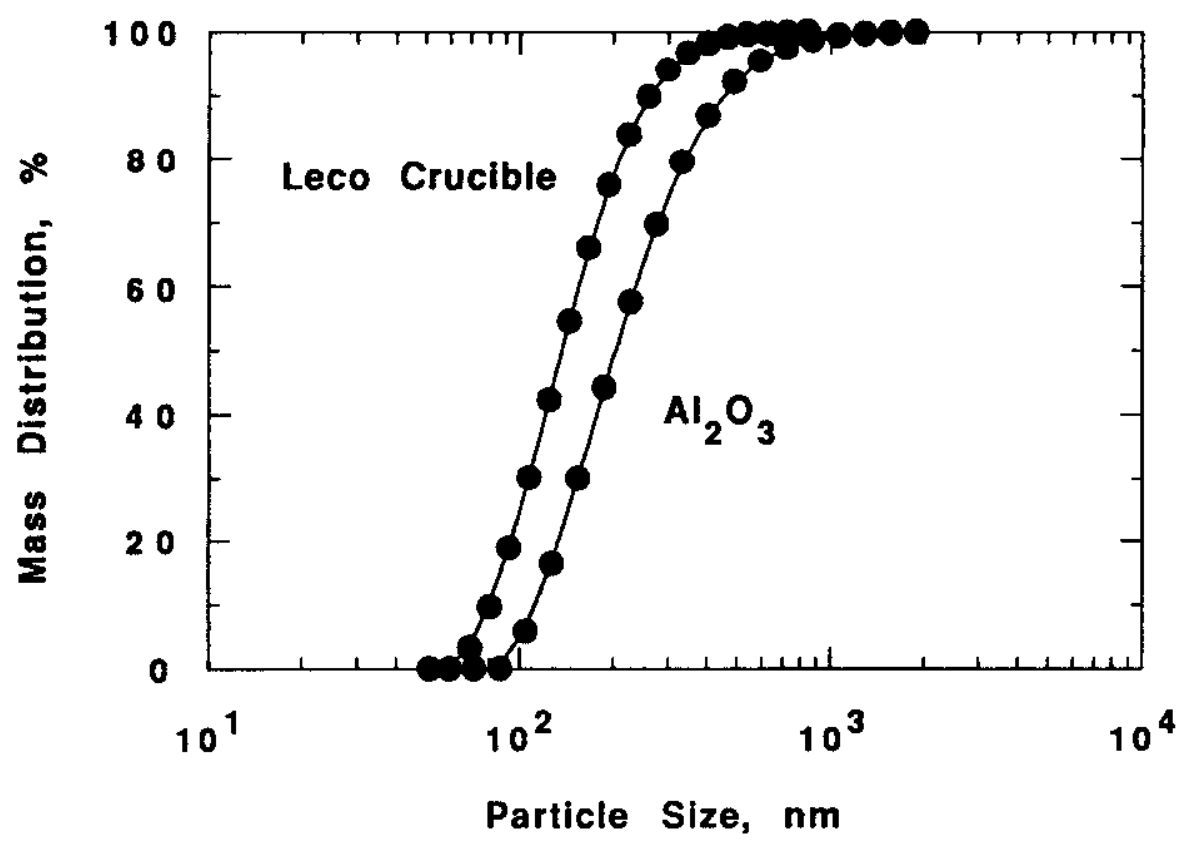

Fig. 1. Cumulative Particle Size Distributions Measured by Light Scattering for Ground LECO Crucible and $\mathrm{Al}_{2} \mathrm{O}_{3}$

The results in Table 2 clearly show that a submicron-sized product could be produced within relatively short grinding times when agate grinding elements are used. After two hours of grinding $\mathrm{Fe}_{2} \mathrm{O}_{3}, 42 \mathrm{wt} \%$ of the product had a particle size of $<1 \mu \mathrm{m}$, and after four hours, $75 \mathrm{wt} \%$ was $<1 \mu \mathrm{m}$. Four to six hours of grinding reduced more than $80 \mathrm{wt} \%$ of most of the other metal axides to $<1 \mu \mathrm{m}$.

For several of the ground samples, the material that was $<2 \mu \mathrm{m}$ was recovered from the Andreasen pipet, and its particle size distribution was remeasured by light scattering. The size distribution curves for the ground $\mathrm{Al}_{2} \mathrm{O}_{3}$ and $\mathrm{LECO}$ crucible are shown in Figure 1. These results indicate that the light scattering measurements agree well with the sedimentation data reported in Table 2.

As with the corundium grinding media, abraston of the agate grinding media led to contamination of the ground metal oxide products. Although the amount of contamination was significantly less than that found with the corundium media, it was enough to be troublesome. Based on mass balance measurements, the extent of silica contamination was estimated to be $0.1-0.5 \mathrm{~g}$, depending on the grinding time and the type of feed. These silica-coated metal oxides exhibited an aqueous biphasic partitioning behavior that was similar to that of amorphous silica $\left(\mathrm{SiO}_{2}\right)$. All of the agate-ground metal oxides except $\mathrm{Al}_{2} \mathrm{O}_{3}$ partitioned into the polyethylene glycol phase at a $\mathrm{pH}$ of 3 . In addition, it was possible to remove the silica coating on the metal axides by dissolution with $\mathrm{NaOH}$ at $\mathrm{pH}>9.5$. After the silica coating was removed in this manner, the metal oxides partitioned to the lower, sodium sulfate phase of a 
sulfate/PEG biphase system. Interestingly, the partitioning behavior of ground $\mathrm{Al}_{2} \mathrm{O}_{3}$ was unaffected by the presence of the contaminating sllica. It partitioned to the lower sulfate phase regardless of whether the contaminating silica was dissolved with $\mathrm{NaOH}$.

Because of the drawbacks of the corundium and the agate grinding media, we initiated grinding tests using zirconia media. As we expected, the zirconia grinding media did not adversely affect the aqueous biphase partitioning of ground metal oxddes. All of the ground metal oxides that we tested. (e.g., $\mathrm{Fe}_{2} \mathrm{O}_{3} . \mathrm{THO}_{2}$, and $\mathrm{Al}_{2} \mathrm{O}_{3}$ ) partitioned preferentially to the sodium sulfate phase in a sulfate/PEG biphase system at a pH of 3. This agrees with the results obtained using corundium grinding media. Unfortunately, the zirconla grinding elements obtained from Fisher, while cylindrical, are not exactly the same height as the corundium and agate elements that were supplied with the mill by McCrone. In addition, the base surfaces of the zirconia grinding elements are slightly convex, resulting in an increased void volume within the mill. As a consequence, the zirconia grinding elements do not provide the element-to-element contact necessary for efficient grinding. We recently received zirconia grinding elements from Dlamonite (Shreve, $\mathrm{OH}$ ) that are identical in size to the agate elements supplied with the McCrone mill, and we will be conducting grinding tests with these elements in the near future.

There are a number of other mill designs that would be more appropriate for grinding to submicron sizes, but they require a minimum feed of approximately $100 \mathrm{~g}$. For example, the United States Bureau of Mines (USBM) has published several reports detailing the design of their turbomill, which has been used to produce wide variety of ultrafine materials [HOYER-1897, -1988, STANCZYK, WTTTMER]. The turbomill was previously used for grinding filler-grade clays and for the beneficiation of glass sand. In the early 1980's, the turbomill was redesigned to its present configuration which consists of a cylindrical container, a stator, and a rotor attached to a drive shaft. The mill is now constructed of ultra-high molecular-weight polyethylene to eliminate all metal contamination originating from the mill [HOYER-1988].

The turbomill has successfully produced submicron-sized ceramic powders of materials such as barium ferrite, calcite, dolomite, fluorspar, silica, zirconia, and aluminum oxide [HOYER-1988]. The grinding media are typically 1-2 mm spherical beads of alumina or zirconta, although Ottawa silica sand has been used as a media for grinding silica catalysts [HOYER-1988]. Alternatively, the mill can be operated in an autogenous mode where by large grains of the material to be ground are used as the grinding media. Typically, material with a particle feed size of 100-200 mesh can be reduced to $80 \mathrm{wt} \%<1 \mu \mathrm{m}$ in as little as $4 \mathrm{~h}$. Results such as these have been achieved even with abrasive ceramics like silicon carbide [HOYER-1988]. Energy requirements to produce ultrafine ceramic powders are reported to be about $526 \mathrm{~kW}-\mathrm{h} /$ ton (526 kW-h/907 kg) [HOYER-1988].

The laboratory-size turbomill has been successfully scaled up, and continuous grinding circuit flowsheets have already been designed. The USBM turbomill has been applied on a commercial scale in the paper-coating and titanlum oxide pigment preparation industries. For example, a 52-in.-dia unit that can process 50,000 tons per year of titanium oxide has been built and is used by Kerr McGee corporation. 
For pllot- and full-scale grinding applications, several other commercially avallable mills could be considered. For example, wet vibratory mills are avallable from SWECO (Florence, KT) that are capable of producing submicron particle sizes. These mills use grinding media that are 0.5- $\times 0.5-\mathrm{in} .(1.27-\mathrm{x} 1.27-\mathrm{cm})$ cylinders made from aluminum oxide or zirconium oxide. Avallable mill capacity ranges from 2.6 to $180 \mathrm{gal}(9.8$ to $681.4 \mathrm{~L})$ and can be operated at maximum pulp densities of $80 \mathrm{wt} \%$ solids. The mill requires 5 to $30 \mathrm{~h}$ to reduce the average particle size to $1 \mu \mathrm{m}$ or less.

Bematek Systems, Inc. (Beverly, MA) manufactures colloid mills with pulp capacities of 1.5 to 3 gal (5.7 to $11.4 \mathrm{~L})$. These mills can reduce particle sizes to the submicron range when the rotor gap is properly adjusted. The rotors are made of aluminum oxide or sllicon carbide. These mills are currently used in industry for grinding pigments, clays, abrasive solids, and fillers.

Union Process (Akron, $\mathrm{OH}$ ) markets attritors that are designed to produce micron-size products. The mill contains internally agitated grinding media and is commonly referred to as a stirred ball mill. The manufacturer reports that it has been used to grind ceramic materials. The mill can use a wide variety of grinding media. Including carbon steel, chrome steel, ceramic, glass, and fint stones. These mills can be operated in batch, continuous, or recirculation modes. They are avallable in sizes ranging from laboratory models with a $750-\mathrm{mL}$ capacity to full-scale production units with a maximum capacity of 10 gal $(37.8 \mathrm{~L})$. Currently, these mills are used industrially to grind agricultural products, rubber, ceramics, metal powders, plastics, and pigments.

Mineral Processing Systems, Inc. (York, PAl produces vertically stirred mills and claims that they can produce ultrafine sizes. In this mill design, the grinding media are stirred by an overhung double helix screw. The mill can handle a maxium feed particle size of $0.25-\mathrm{in}$. $(0.64-\mathrm{cm})$ and can produce product sizes of $75 \mu \mathrm{m}$ or less. The mill is operated wet and can be run in either batch or continuous mode. The available capacities range from 1 to 100 tons $(907$ to $90718 \mathrm{~kg})$ per hour. The most efficient way to produce ultrafine product sizes is to grind in stages. A mill of this type could be used to prepare a feed to the final grinding stage for producing a submicron product.

Because of the low volume of Pu-residues relative to the amount of materals ground commercially to micron and submicron sizes, any of the mills described above should be adequate. A single, full-scale mill should be able to produce about $4000 \mathrm{~kg}$ of submicron material per year, assuming a $15-\mathrm{h}$ grind time.

\section{Phase Diagrams}

Phase diagrams will be needed to design aqueous biphasic solvent extraction processes. For a number of aqueous biphase systems, they are already available in the literature. However, most of the systems that have been studied are primarily applicable to biological separations. Consequently, we have begun to measure phase diagrams for systems that we think can be applied to waste treatment systems. While doing so,we have also explored the use of a radiotracer technique for measuring the tie lines of phase diagrams. If the appropriate radiotracers are available, their use can significantly reduce the data acquisition time and thereby enable a series of tie lines to be determined in a single day. 
Phase diagrams for the sodium sulfate/PEG system are shown in Fig. 2. The polymer had an average molecular weight of 10,000 and was purchased from Aldrich. By convention, the ordinate refers to the concentration of the polymer distributing preferentially in the top phase, while the abscissa refers to the concentration of the salt distributing preferentially in the bottom phase. Systems in which the compositions lie above the binodial are biphasic, while those below the binodial are monophasic.

Temperature can have a dramatic effect on phase behavior, as shown in Fig. 2. For the sodium sulfate/PEG system, the biphase forms more readily at higher temperatures. The same is true of the potasslum phosphate/PEG system [ALBERTSSON]. However, this is not true of all aqueous biphase systems. By contrast. the dextran/PEG system has a tendency to become biphasic more readily at lower temperatures, while the dextran/methylcellulose system is little affected by temperature [ALBERTSSON].

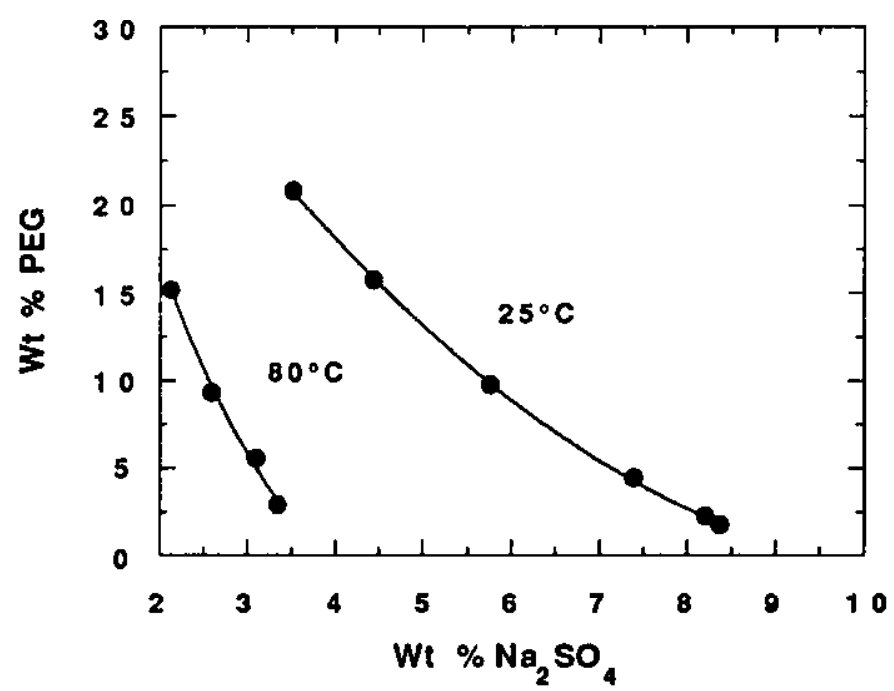

Fig. 2. Phase Diagram for the PEG-10,000/Sodium Sulfate System at $25^{\circ}$ and $80^{\circ} \mathrm{C}$ [CHAIKO-1989]

The molecular weight of the PEG also influences phase behavior. This is shown in Fig. 3, where phase diagrams for PEG-3400 and PEG-10000 are plotted. Increasing the molecular weight of the polymer shifts the binodial to the left. This is generally beneficial, since a lower polymer concentration usually leads to a reduction in the viscosity of the polymer phase. However, it must be remembered that at equal concentrations, the higher molecular weight polymer solution will have a greater viscosity. Therefore, a balance between molecular weight and phase viscosity must be considered in designing an aqueous biphase system. 


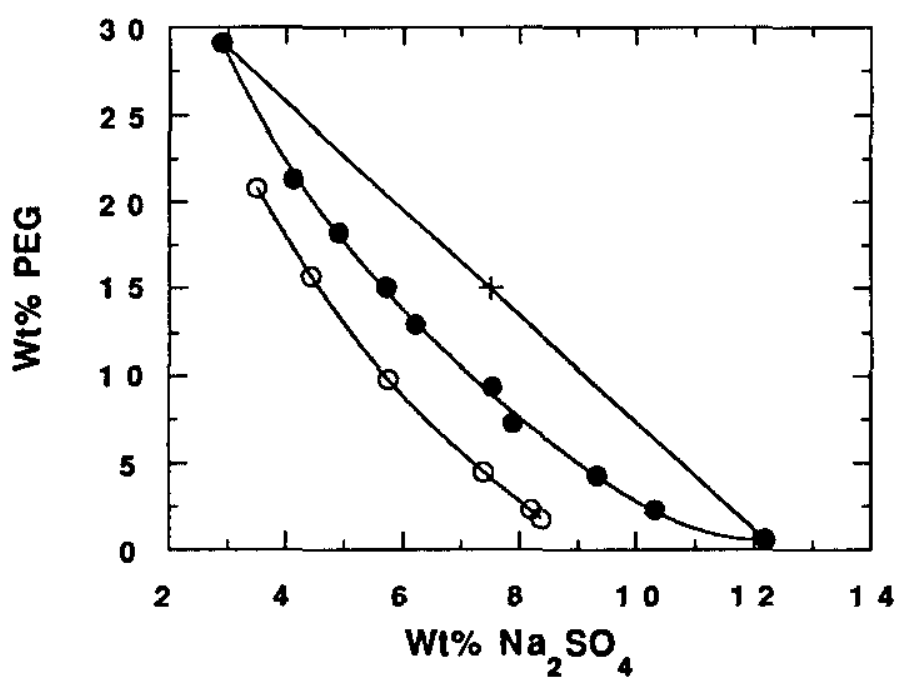

Fig. 3. Phase Dlagram of the PEG/Sodium Sulfate System at $25^{\circ} \mathrm{C}$. The open symbols are PEG-10,000 and the closed symbols are PEG-3400.

In Fig. 3, the compositions of the top and bottom phases are represented by the intersection points of the tie line with the binodial. For example, a total system composition of $15 \% \mathrm{PEG} / 7.5 \%$ sodium sulfate is represented by the cross on the tie line. Intersection of the tie line with the binodial indicates that the top phase composition is about 30\% PEG and 3\% sodium sulfate. while that of the bottom phase is about $0.5 \%$ PEG and $12 \%$ sodium sulfate.

Approximate phase volume ratios are estimated from the distance ratio on the tie line between the point at the total system composition and the two segments of the tie line that intersect the binodial. This ratio is actually the weight ratio of the system, since composition is represented in units of wt \%; but since the densities of the top and bottom phases are 1.04 and $1.09 \mathrm{~g} \mathrm{~mL}^{-1}$, respectfvely, the phase volume and phase weight ratios are approximately equal.

By measuring multiple numbers of tie lines and extrapolating along their midpoints to the binodial leads to the critical (or plait) point. At the critical point, the compositions of both phases are identical with nearly equal volumes. The interfacial tension is exceedingly low within the the critical region but increases with distance from the critical point. The logarithm of the interfacial tension has been shown to be proportional to the length of the tie line [BAMBERGER, RYDEN, SCHUERCH].

Normally, the position of a tie line is determined from chemical analysis of the top and bottom phases. An alternative method, which was used in generating Fig. 3 , involved measuring the phase volume ratio, the densities of each phase, and the partition coefficients of PEG and sodium sulfate. All of these values were determined at a total system composition represented by the cross in the phase diagram. 
The phase volume ratios were measured using Wintrobe tubes graduated from 0 to $105 \mathrm{~mm}$ in $1-\mathrm{mm}$ intervals. The phase densities were measured so that phase volume ratios could be converted to phase weight ratios. Partition coefficients were measured using ${ }^{35} \mathrm{~S}$-labeled sulfate and ${ }^{3} \mathrm{H}$-labeled PEG-3400. The partition coefficlents for sulfate and PEG were found to be 0.24 and 52.8, respectively. The compositions of the top and bottom phases with respect to PEG and sulfate were calculated from the partition coefficient, defined as $\mathrm{C}_{t} / \mathrm{C}_{\mathrm{b}}$, and the following mass balance expression:

$$
V_{t} d_{t} C_{t}+V_{b} d_{b} C_{b}=\left(V_{t} d_{t}+V_{b} d_{b}\right) C_{b}
$$

where the subscripts $t$ and $b$ refer to the top and bottom phases, respectively; and $V, d$, and $\mathrm{C}$ refer to volume, density, and concentration, respectively. Concentrations are expressed in units of $w t \%$. The term $\mathrm{C}_{o}$ is the overall concentration based on the total system volume.

Binodial curves were determined by adding known amounts of water into a series of biphasic mixtures untll the transition to a monophasic system was observed. The transition from biphasic to monophasic was indicated by the absence of any cloudiness when the solutions were shaken by a vortex mixer. All solutions were equilibrated at $25^{\circ} \mathrm{C}$, and, near the water titration endpoint, the water additions were made in $5-\mu \mathrm{L}$ increments using a microliter syringe. Thus, the position of the binodial can be determined very accurately. By using the radiotracers, a series of tie lines can eastly be determined in a single day.

Some other salts that have been reported to generate a biphase with PEG-3400 are sodium carbonate, sodium hydroxide, sodium phosphate, and ammonium sulfate [ANANTHAPADMANABHAN-1987B]. Unfortunately, sodium nitrate does not form a biphase with PEG. However, we have found that PPG-425 (polypropylene glycol) does form a biphase with sodium and aluminum nitrate, sodium and ammonium carbonate, sodium sulfate, potasslum chloride, and ammonium chloride. In the coming year, we plan to measure the phase diagrams of a number of PEG and PPG systems that would be compatible with waste treatment needs and existing solutions that are inventoried by the DOE .

\section{Interfaclal Properties of Polymeric Pu(IV)}

Studies of the interfacial and colloidal properties of polymeric Pu(IV) were initiated in FY91. These studies will help us to understand the partitioning behavior of plutonium in aqueous biphasic extraction systems. A significant portion of the extraction studies focus on the use of polymeric Pu(IV) as a model to predict the partitioning behavior of submicron $\mathrm{PuO}_{2}$ particulates. Other aspects of the extraction studies focus on the development of aqueous biphasic extraction systems to separate and recover hydrous plutonium polymers from neutral or alkaline waste solutions. Extraction measurements of polymeric $\mathrm{Pu}(\mathrm{IV})$ and ground $\mathrm{PuO}_{2}$ will show how well polymeric $\mathrm{Pu}(\mathrm{IV})$ serves as a model for ground $\mathrm{PuO}_{2}$.

The interfacial and colloidal properties of polymeric Pu(IV) are being studied by interfacial adsorption measurements and dynamic laser light scattering 
measurements. By makdng these measurements, it will be possible to ascertain if the interfacial and bulk liquid/liquid phase partitioning behavior of polymeric Pu(IV) can be correlated with polymer size and surface charge. In addition, the surface properties of ground $\mathrm{PuO}_{2}$ will be studied by measuring the electrophoretic mobllities of both lowand high-fired $\mathrm{PuO}_{2}$ samples.

A number of Pu-polymers were prepared by $\mathrm{M}$. Toth of Oak Ridge National Laboratory and were characterized by Thlyagarajan et al. [THIYAGARAJAN] using small-angle neutron scattering (SANS). The preparation of the polymer solution, which has been described in detall, is designated as sample 4 in the publication by Thiyagarajan et al. From the SANS measurements, they concluded that the Pupolymer is ellipsoidal, with a diameter of $22 \AA$ and a length of $120 \AA$. The Pu atoms are linked through oxygen bridges. X-ray diffraction patterns of aqueous $\mathrm{Pu}$-polymer solutions resembled those reported for crystalline $\mathrm{PuO}_{2}$.

Our initial studies of colloidal Pu(IV) examined the effect of high lonic strength on the stability of polymeric Pu(IV) solutions. The polymerized plutonium used in these studies was obtained from $\mathrm{H}$. Dlamond (Argonne National Laboratory. Chemistry Division). A stock solution of plutonium-239 polymer was prepared in $0.5 \mathrm{M} \mathrm{HNO}_{3}$. Precipitation of polymeric Pu(IV) from aqueous solutions at high lonic strengths was studied by splking $6 \mu \mathrm{L}$ of the Pu-polymer stock $\left(2.2 \times 10^{5} \mathrm{cpm} / \mu \mathrm{L} ; 6.8 \mathrm{mM}\right)$ into $2 \mathrm{~mL}$ of each of the following $7.5 \mathrm{wt} \%$ electrolyte solutions: sodium sulfate, sulfuric acid, nitric acid, and sodium nitrate. Thus, the initial Pu concentrations were about $20.4 \mu \mathrm{M}$. A parallel set of experiments were carried out in which the solutions were contained in either glass or polyethylene vials. The electrolyte solutions were sampled and assayed by liquid scintllation counting. In each case, the solutions were vortexed just prior to sampling.

Adsorption data for the four electrolyte solutions are shown in Figs. 4 and 5 . where the fractional amount of plutonium remaining in solution $\left(C / C_{o}\right)$ is plotted as a function of time. With the exception of the sulfuric acid system, there was initially a rapid decrease in bulk aqueous phase plutonium concentration followed by a gradual decrease that continued untll an equilibrium concentration was reached after about $18 \mathrm{~h}$. Surprisingly, the polymeric Pu(IV) was stable in the sulfuric acid system, showing no significant loss in Pu concentration over the 24-h period.

The decrease in plutonium concentration shown in Figs. 4 and 5 is believed to be due primarily to adsorption of the plutonium polymer onto the glass surface of the container rather than from growth and precipitation of large colloidal particles. Evidence for an adsorption mechanism is found in Fig. 6, where a parallel set of experiments were carried out using borosilicate glass and polyethylene vials. It is clear that the composition of the vial significantly effects both the rate of adsorption and the equilibrium plutonium concentration in solution. The rate of adsorption and the equilibrium adsorption density are both greater for polyethylene surfaces than for borosilicate glass. If the decrease in plutonium concentration resulted from particle aggregation and precipitation in the high ionic strength solutions, then the choice between glass and plastic vials should not have had any influence on the equilibrium concentration of plutonium remaining in solution. 


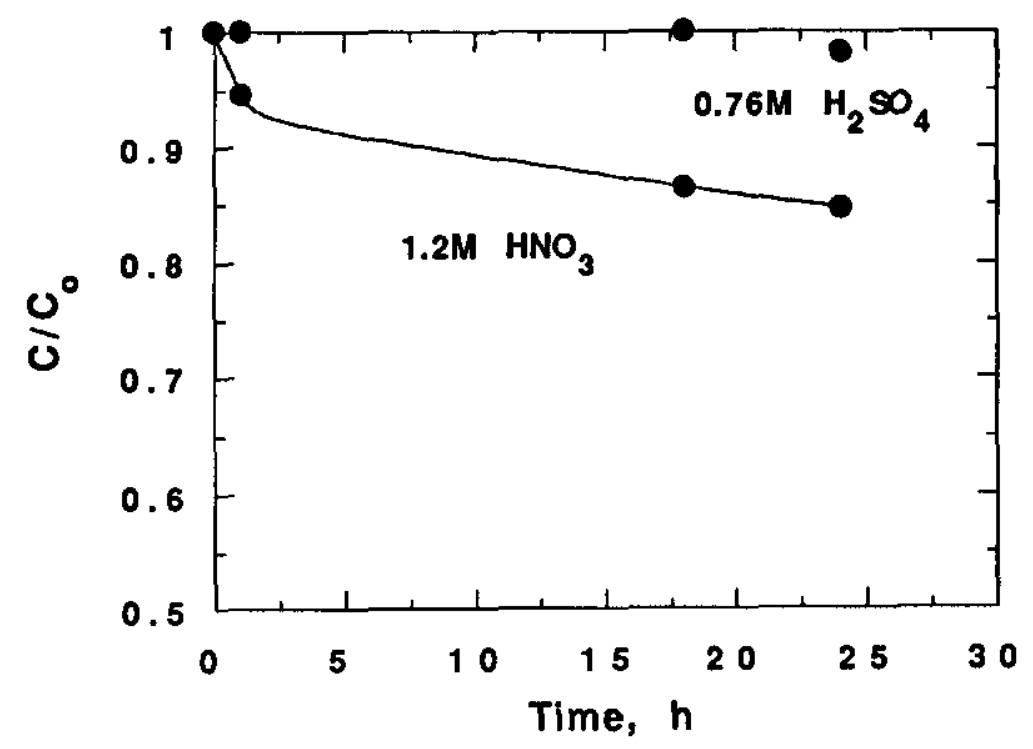

Fig. 4. Adsorption of Polymeric Pu(IV) onto Glass from $7.5 \mathrm{wt} \%$ Sulfuric and Nitric Acid Solutions at $25^{\circ} \mathrm{C}$

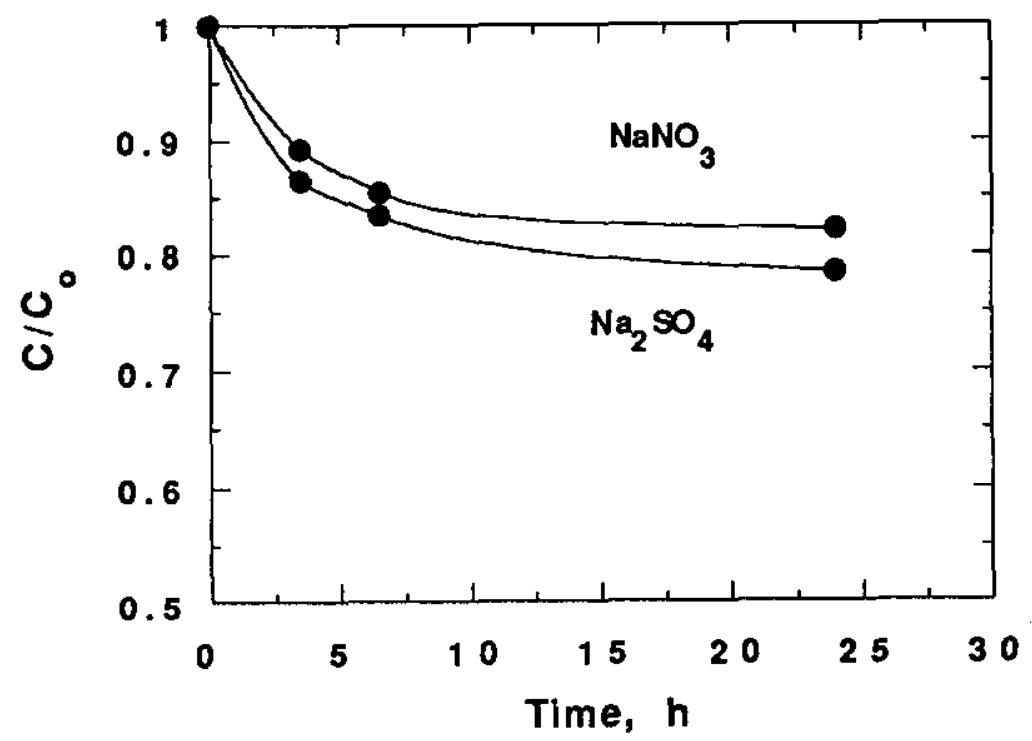

Fig. 5. Adsorption of Polymeric Pu(IV) onto Glass from 7.5 wt \% Sodium Sulfate and Sodium Nitrate Solutions at $22^{\circ} \mathrm{C}$ 


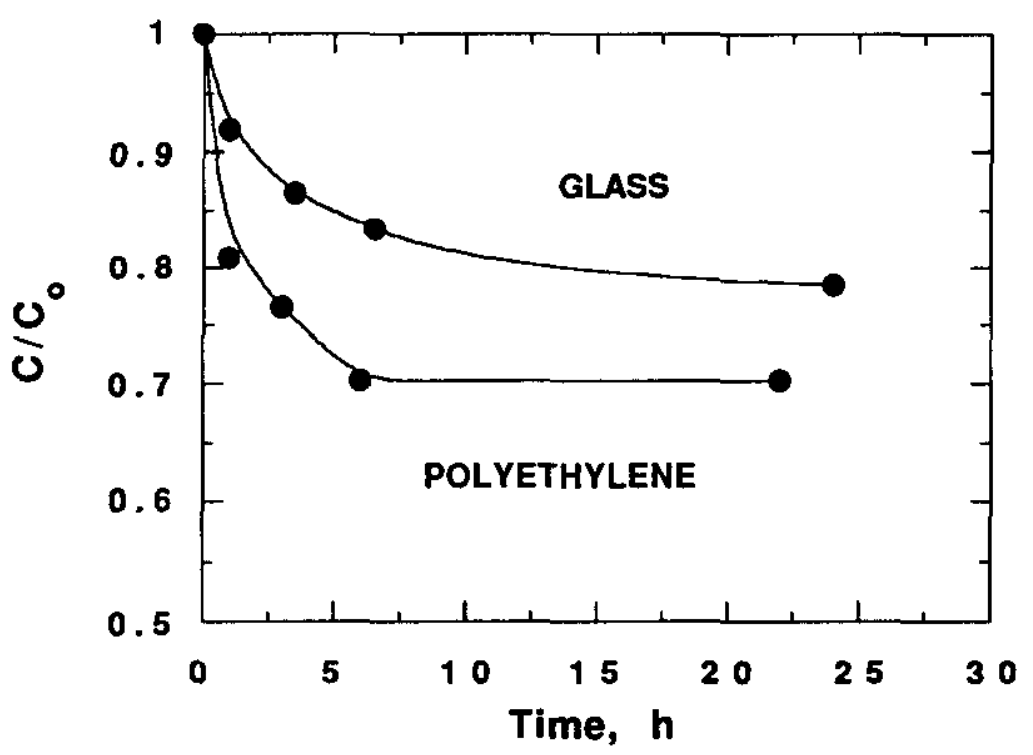

Fig. 6. Adsorption of Polymeric Pu(IV) onto Glass and Polyethylene from 7.5 wt \% Sodium Sulfate Solutions at $22^{\circ} \mathrm{C}$

As expected, the adsorption density of polymeric Pu(IV) at solid/liquid interfaces is reported to be dependent upon the type and number of surface adsorption sites, the physico-chemical properties of the colloidal Pu species, and the composition of the aqueous phase [OCKENDEN, CARNIGLIA].

Perhaps the most surprizing aspect of the adsorption studies is the fact that in sulfuric acld solutions, the polymer appears to be resistant to adsorption onto borosilicate glass (see Fig. 4). The adsorption data seem to suggest that colloidal Pu(IV) is rapidly dissolved in sulfuric acid solutions at room temperature. This is considered unlkely given the extraordinary resistance of aged polymeric Pu(IV) to dissolution by $\mathrm{HNO}_{3}$ and $\mathrm{HNO}_{3} / \mathrm{HF}$ mixtures [CLEVELAND-1979].

Of the various tetravalent metal ions that form hydrous polymeric species (e.g.. $\mathrm{Zr}, \mathrm{Hf}, \mathrm{Ce}, \mathrm{Th}, \mathrm{U}$, and $\mathrm{Pu}$ ) only $\mathrm{U}$ and $\mathrm{Pu}$ undergo hydrolysis leading to colloidal species that appear not to be in equilibrium with low molecular weight intermediates [CLEVELAND-1967, GIMBLETT]. For example, the existence of hydrolyzed Pu(IV) dimers, trimers, and other such low molecular weight species has never been demonstrated experimentally [GIMBLETT].

The nonequilibrium nature of colloldal Pu(IV) species is demonstrated in Fig. 7. On day one of the experiment, a polymeric Pu(IV) solution in 7.5 wt \% sodium sulfate was allowed to equilibrate in a borosilicate glass vial. The decrease in Pu concentratIon as a function of time shows that the bulk aqueous phase concentration of $\mathrm{Pu}$ had stabilized within $24 \mathrm{~h}$. This solution was then transferred to a second glass vial and the 


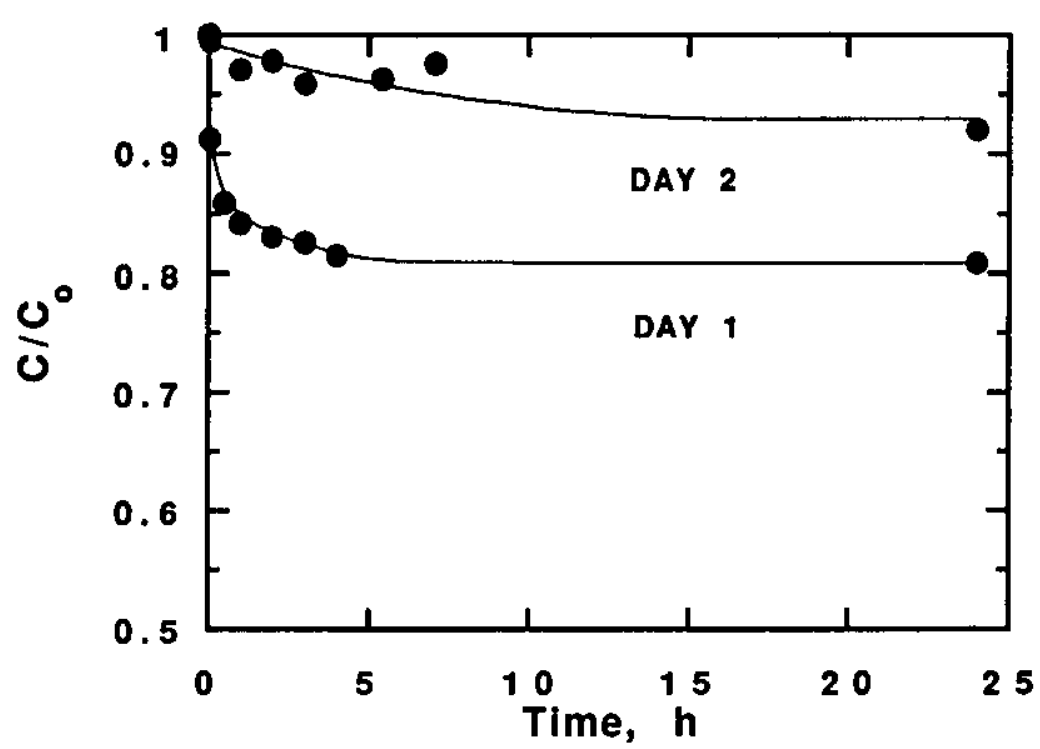

Fig. 7. Adsorption of Polymeric Pu(IV) onto Successive Glass Vials From 7.5 wt \% Sodium Sulfate at $22^{\circ} \mathrm{C}$

Pu concentration was again monitored as a function of time. On the second day. however, the extent of Pu adsorption at the solid/liquid interface was significantly lower than that observed on the first day. Apparently, the surface properties of colloidal Pu(IV) species are variable, giving rise to more than one adsorption equilibrium constant.

The adsorption data in Fig. 7 can be used to demonstrate this point. The partitioning of Pu between the bulk aqueous phase and the glass/liquid interface can be described by the following equilibrium:

$$
K_{1 / a}=C_{1} / C_{a}
$$

where $K_{1 / a}$ is the partition coefficient, $C_{l}$, and $C_{a}$ refer to the Pu concentrations at the glass/liquid interface and the bulk aqueous phase, respectively. The partition coefficient is related to the free energy of adsorption ( $\Delta \mathrm{G}^{\circ}$ ads) as follows:

$$
\mathrm{K}_{\mathrm{I} / \mathrm{a}}=\exp \left(-\Delta \mathrm{G}^{\circ} \mathrm{ads} / \mathrm{RT}\right)
$$

In addition, $\Delta \mathrm{G}^{\circ}$ ads can be expressed as a summation of the various contributions to the free energy of adsorption:

$$
\Delta \mathrm{G}_{\text {ads }}^{\circ}=\left[\Delta \mathrm{G}_{\text {adslp }}^{\circ}-\mathrm{zF} \psi^{\circ}\right.
$$

where the subscript $\mathrm{p}$ refers to uncharged, polar group interactions, and $\mathrm{zF} \psi^{\circ}$ is the potential energy of charged polar group interactions; $z$ is the effective valence of the Pu collold, F is Faraday's constant, and $\psi^{\circ}$ is the surface potential of the glass. 
Since the temperature and the fonic strength were kept constant, the partition coefficient should also have remained constant. The term $C_{1}$ in Eq. 2 can be calculated from the mass balance of the total alpha activity introduced onto the system ( $\left.\mathrm{C}_{\text {total }}\right)$ and the amount of activity remaining in solution at equilibrium:

$$
K_{1 / a}=\alpha\left(C_{\text {total }}-C_{a}\right) / C_{a}
$$

where $\alpha$ is the volume-to-surface-area ratio of the system. Substituting the data in Fig. 7 into Eq. 5 glves $K_{i / a}$ (day 1$) / K_{1 / a}$ (day 2) $=0.234 / 0.087=2.69$. This implies that a range of $K_{1 / a}$ exists due to variation in the surface chemical properties of colloidal Pu(IV). The most probable factors affecting $K_{1 / a}$ are particle size and shape and the presence of strongly adsorbed species on the colloid surface.

Another way of describing the partitioning of colloldal Pu(IV) between the solid/liquid interface is in terms of the Langmuir adsorption isotherm:

$$
\Gamma=\Gamma^{\infty} \mathrm{KC}_{\mathrm{a}} /\left(1+\mathrm{KC}_{\mathrm{a}}\right)
$$

where $\Gamma^{\infty}$ is the adsorption density at interfacial saturation and $\mathrm{K}$ is a constant describing the efficiency of adsorption. At low colloidal Pu(IV) concentrations, $\mathrm{KC}_{\mathrm{a}} \ll 1$, and Eq. 6 reduces to

$$
\Gamma=\Gamma^{\infty} \mathrm{KC}_{\mathrm{a}}
$$

Thus, Eqs. 5 and 7 are equivalent with $K_{i / a}=\Gamma^{\infty} \mathrm{K}$. Under the conditions in which the adsorption experiments were conducted, the maximum adsorption density observed on day one was $0.053 \mu \mathrm{g} \mathrm{Pu} / \mathrm{cm}^{2}$. This is only about $3 \%$ of the $\Gamma^{\infty}$ value $\left(1.6 \mu \mathrm{g} \mathrm{Pu} / \mathrm{cm}^{2}\right.$ ) reported by Ockenden and Welch [OCKENDEN]. Their aqueous phase composition was $1-3 \mathrm{mg} \mathrm{Pu} / \mathrm{cm}^{3}$ and $0.1 \mathrm{M} \mathrm{HNO}_{3}$. The adsorption data of Carniglia [CARNIGLIA] also produce a similar value for $\Gamma^{\infty}$. These data are plotted in Fig. 8 according to the linear form of the Langmuir adsorption isotherm:

$$
1 / \Gamma=1 /\left(\Gamma^{\infty} \mathrm{KC}_{\mathbf{a}}\right)+1 / \Gamma^{\infty}
$$

Only the 6-h equilibration data of Carniglia are shown in Fig. 8. Adsorption data collected at equilibration times of $3 \mathrm{~h}$ or less are not considered to be at equilibrium and did not fit the straight line plot in Fig. 8. From the slope and intercept of the straight line in Fig. 7, $\Gamma^{\infty}$ and $\mathrm{K}$ are found to be $3.87 \times 10^{-9} \mathrm{~mol} / \mathrm{L}$ (or $0.92 \mu \mathrm{g}$ $\mathrm{Pu} / \mathrm{cm}^{2}$ ) and $4.5 \times 10^{5} \mathrm{~L} / \mathrm{mol}$, respectively. Carniglia [CARNIGLIA] also reported a colloidal Pu(IV) adsorption density of $0.18 \mu \mathrm{g} \mathrm{Pu} / \mathrm{cm}^{2}$ on glass for the $0.5 \mathrm{M} \mathrm{Na}_{2} \mathrm{SO}_{4} /$ $0.01 \mathrm{M} \mathrm{HNO}_{3}$ system at room temperature. The equilibrium aqueous phase $\mathrm{Pu}$ concentration, however, was only $21.1 \mu \mathrm{M}\left(5.05 \mu \mathrm{g} / \mathrm{cm}^{3}\right)$. As a result, this adsorption density would not be considered an interfacially saturated value. 


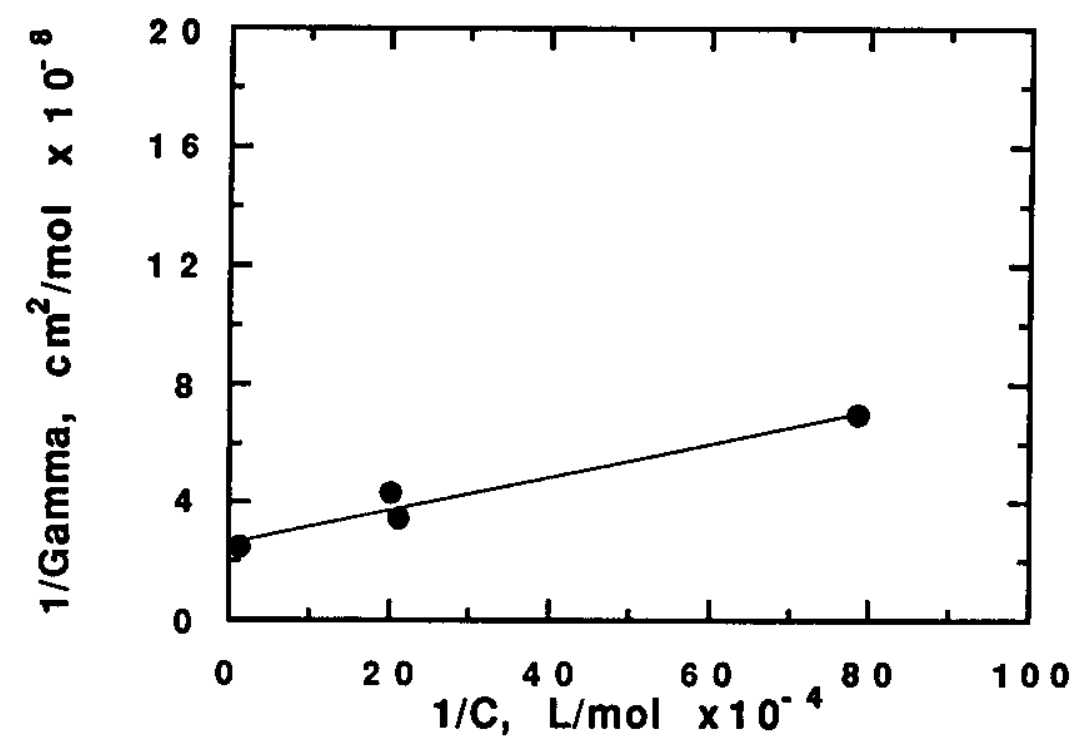

Fig. 8. Langmiur Plot for Colloidal Pu(IV) Adsorption onto Glass. The aqueous phase contained $0.1 \mathrm{M} \mathrm{HNO}_{3}$. Data obtained from Carniglia [CARNIGLIA].

The variable adsorption densities observed in Fig. 7 indicate that the various colloidal Pu(IV) species present in solution are not at equilibrlum with each other. This in itself should not cause any problem in using colloidal Pu(IV) as a model system for particulate $\mathrm{PuO}_{2}$. In fact, if the polymeric $\mathrm{Pu}$ species were in equilibrium with monomeric Pu(IV), then this would not be an appropriate model system. However, it is unclear whether the variations in the surface properties of the colloidal Pu(IV) species are sufficient to interfere with the complexation of the colloid by phase transfer agents and the subsequent partitioning of polymeric Pu(IV) in aqueous biphase systems.

In aqueous biphasic extraction systems, surfactants and complexants are used to promote the selective phase transfer of colloidal particulates. The effect of these phase transfer agents (PTAs) on the stabllity of colloidal Pu(IV) at high tonic strengths was also investigated. The PTAs used were sodium bis(2-ethylhexyl) sulfosuccinate (Aerosol OT or AOT) and dextran (Industrial grade purchased from Sigma Chemical Co.. average molecular weight 19,600). Dextran was examined because it is used in generating aqueous biphase systems and also in mineral flotation systems as a surface modifler.

Adsorption data for polymeric Pu(IV) solutions containing AOT and dextran are shown in Figs. 9 and 10 for the borosilicate glass and polyethylene systems. In both cases, the dextran enhanced the adsorption of colloidal Pu(IV) at the solid/liquid interface, while AOT inhibits this behavior. As in Fig. 6, plutonium adsorption onto polyethylene was greater than that onto borosllicate glass. Comparison of the data in Fig. 6 with that in Figs. 9 and 10 indicates that the adsorption behavior in the absence 
of any additives is fairly reproducible. The degree to which AOT inhibits polymeric $\mathrm{Pu}(\mathrm{IV})$ from adsorbing at the solid/liquid interface is astounding. For example, there was no detectable loss of Pu from the electrolyte solutions even after $24 \mathrm{~h}$.

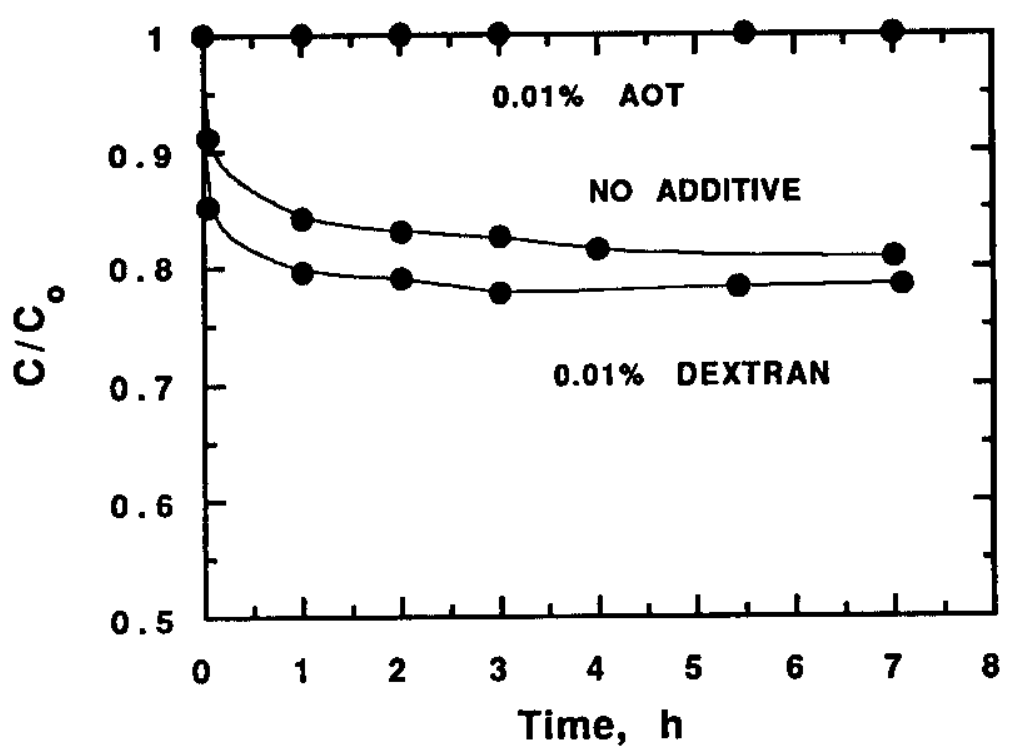

Fig. 9. Effect of AOT and Dextran on the Adsorption of Polymeric Pu(IV) onto Glass from $7.5 \mathrm{wt} \%$ Sodium Sulfate Solutions at $22^{\circ} \mathrm{C}$

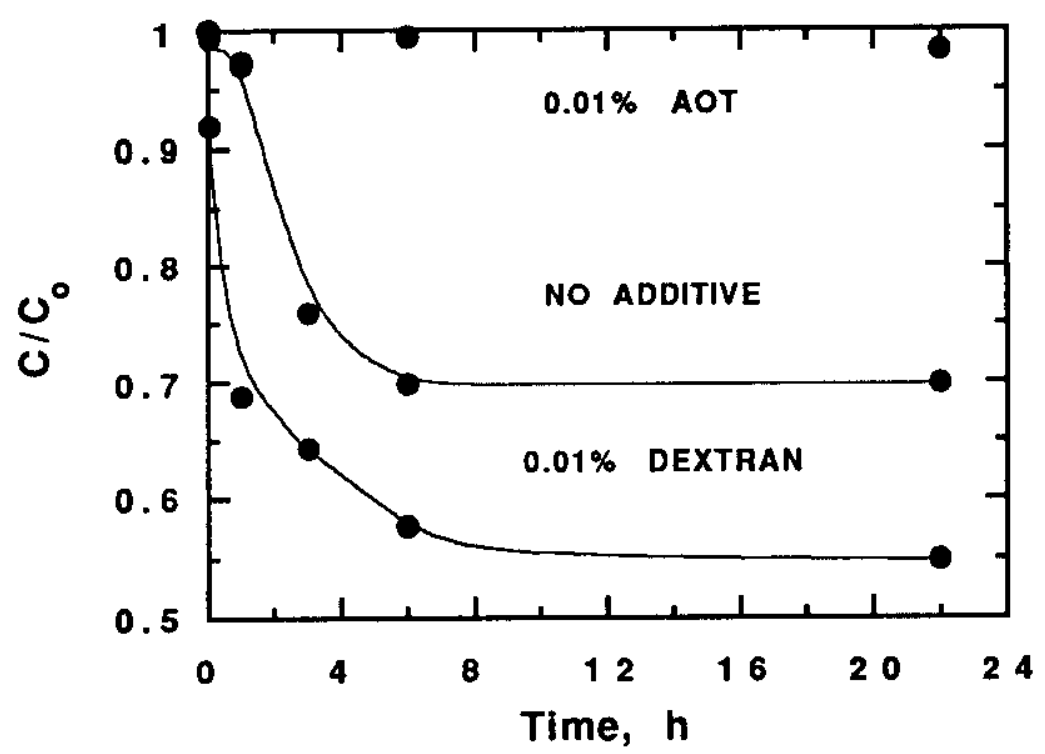

Fig. 10. Effect of Additives on the Adsorption of Polymeric Pu(IV) onto Polyethylene from $7.5 \mathrm{wt} \%$ Sodium Sulfate at $22^{\circ} \mathrm{C}$ 
Because of the balance between the hydrophilic sulfonic acid group and the hydrophobic R-chains, AOT is soluble in a wide vartety of solvents, forming micelles in aqueous solutions and inverted micelles in organic solvents such as hexane, dodecane, and toluene [ROSEN-1989A]. The colloldal properties and uses in conventional oll/water solvent extraction systems of AOT are discussed by a number of authors in the publication edited by PIleni [PILENI]. The abllity of AOT to partition preferentially into oll phases from aqueous phases of high tonic strengths is well known [PILENI]. Because of the ability of AOT to complex colloldal Pu(IV) and to inhibit interfacial adsorption, the effect of this surfactant on the extraction of polymeric Pu(IV) in oll/water systems was examined in some detall. This investigation led to the development of a microemulsion-based solvent extraction system capable of extracting polymeric $\mathrm{Pu}(\mathrm{IV})$ from dilute $\mathrm{HNO}_{3}$ solutions with partition coefficients greater than 1000 and with bulk phase recoveries of Pu as high as 100\% [CHAIKO-1992]. Because the nature of those studies lies outside the scope of this report they will not be described here. However, the effect of AOT on the aqueous biphasic extraction of Polymeric Pu(IV) is described later in Section II-I of this report.

A wide range of starches and polysaccharides are used in mineral flotation systems as surface modiflers for promoting selective particle flotation [FUERSTENAU1962]. Dextrin, an enzyme degradation product of starch, is one of the most commonly used reagents of this class. Since the amylase enzymes used in the degradation reactions can not hydrolyze the $\alpha(1 \rightarrow 6)$ linkages at the branch points of the starch molecule, dextrins are highly branched molecules. Dextrans are branched polysaccharides of $\mathrm{D}$-glucose, but, unlike starch, dextrans have other branch points in addition to the $\alpha(1 \rightarrow 6)$ linkages [LEHNINGER]. While we have found that both dextrin and dextran form an aqueous biphase with PEG-3400, dextrin is much less effective and requires a system composition of at least 7.5\% dextrin/15\% PEG-3400. The dextrin used was purchased from Sigma and was derived from potato starch. In contrast to the dextrin system, the phase diagram for the dextran/PEG-4000 system indicates that a biphase with a 1:1 phase ratio can be generated with 7\% dextran/7\% PEG-4000 [ALBERTSSON].

Starches and dextrin are known to interact strongly with hydrolyzed metal ions [LIU]. In the case of dextrin, the interaction appears to take place through chemical bonding between the hydroxyl groups on the glucose ring and the neutral metal hydroxide spectes [LIU]. It is highly probable that the glucose units in dextran could undergo similar complexation reactions with metal hydroxides. In fact, the adsorption data in Figs. 9 and 10 indicate that dextran is able to form complexes with hydrous metal polymers such as polymeric Pu(IV). While these complexants may have applications in the removal of hydrolyzed metals, including the actinides, from aqueous waste streams, the dextrins and dextrans appear to be of little value in preparing aqueous biphase systems for partitioning of metal lons or metal oxide particulates. Starches and their derivatives do not form biphase systems with inorganic electrolytes as PEG does. In addition, the dextrans partition preferentially into the salt phase in PEG/salt systems [ALBERTSSON], as do metal oxides, even in the absence of dextran. 


\section{E. Laser Light Scattering}

We intend to use both static and dynamic light scattering measurements, where feasible, to characterize the structure of polymeric Pu(IV) species and to correlate the partitioning behavior of colloidal $\mathrm{Pu}$ with particle aggregation phenomena, interfacial adsorption, and complexation by surfactants and macromolecules. In addition, we plan to use light scattering, in conjunction with SANS, to study critical point phenomena that give rise to aqueous biphase formation in aqueous polymer/salt solutions.

Dynamic and static light scattering measurements can be used to deduce structural properties (e.g., particle-size distribution and shape) and kinetic processes (e.g., fractal dimension). In static light scattering techniques, the scattering intensity (I) is measured as a function of either the scattering angle $(\theta)$ or the scattering wave vector $(q)$. The slope from a plot of $\ln (q 1)$ vs. $q^{2}$ provides a measure of particle size (radius of gyration, $\mathrm{R}_{\mathrm{g}}$ ) independent of assumptions regarding shape. The radius of gyration obtained from these measurements is valid for particle diameters larger than $30 \mathrm{~nm}$, where an angular dependence of scattering intensity is observed.

Under dynamic conditions, the diffusion coefficient (D) of particles undergoing Brownian motion is calculated from the autocorrelation function with the following expression [PHILLIES]:

$$
\frac{1}{D}=\tau_{c}\left[\frac{4 \pi n}{\lambda} \sin \frac{\theta}{2}\right]^{2}
$$

where

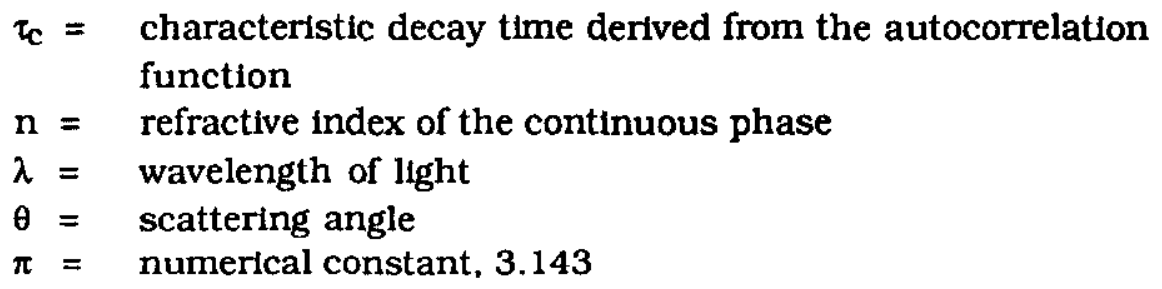

The group of terms within the brackets of Eq. 9, namely, $[(4 \pi n / \lambda)(\sin \theta / 2)]$, is often refered to as the scattering wave vector (q).

The hydrodynamic radius is obtained from the well-known Stokes-Einstein relationship:

$$
R_{h}=k_{B} T /(6 \pi \eta D)
$$

where

$$
\begin{aligned}
& R_{h}=\text { hydrodynamic radius } \\
& \mathbf{k}_{B}=\text { Boltzmann's constant } \\
& T=\text { temperature in degrees Kelvin } \\
& \eta=\text { viscosity of solvent } \\
& D=\text { diffusion coefficient }
\end{aligned}
$$


A monodisperse collection of spherical particles gives rise to an intensity autocorrelation function $\left(\mathrm{G}^{(2)}(\tau)\right)$ that is a single, decaying exponential function

$$
G^{(2)}(\tau)=A+B \exp \left(-2 D k^{2} \tau_{c}\right)
$$

where $A$ is the baseline of the function and is equal to the square of the average scattering intensity and $B$ is an instrumental constant. For a distribution of particles, the intensity autocorrelation function becomes a sum of decaying exponentials

$$
G^{(2)}(\tau)=A+\left[\int_{0}^{\infty} B(N) e^{-D(N) q^{2} \tau_{a}} d N\right]^{2}
$$

The Laplace inversion of Eq. 12 must be performed in order to extract the particle size distribution. This operation in itself is quite formidible and, unfortunately, there are an infinite number of possible solutions that will satisfy Eq. 12 to within the experimental error of the measured correlation function [STOCK]. To simplify the problem, a distribution form must be assumed in order to arrive at a unique solution. Alternatively, the sample can be fractionated into narrow size limits before making the scattering measurements. If this is done, or if the size distribution is very narrow to begin with, the method of cumulants can be used to obtain an approximate solution to Eq. 12 [STOCK]. In this approach, the correlation function is expressed in terms of the cumulants or central moments of the distribution of the decay rates:

$$
0.5 \ln (G(\tau)-G(\infty))=C_{0} \cdot \bar{\Gamma} \tau+\frac{1}{2 !} \mu_{2} \tau^{2}-\frac{1}{3 !} \mu_{3} \tau^{3}
$$

where $\bar{\Gamma}=\overline{\mathrm{D}} \mathrm{q}^{2}$ and $\mu_{2}$, the second cumulant, is equal to $(\Gamma-\bar{\Gamma})^{2}$. The third and fourth cumulants provide values for the skewness and kurtosis in the distribution $G(\Gamma)$. Due to statistical errors in the experimental data, cumulants higher than the second are usually considered to be of little value. Because Eq. 13 is an infinite series that has been truncated at the second or third term, it can not be expected to approximate anything other than fairly narrow $\left(\mu_{2} / \vec{\Gamma}^{2} \leq 0.3\right)$ line width distribution functions.

Consequently, fitting of broad or multimodal distributions should not be attempted with the cumulant expansion method [CHU].

A linear least squares analysis can be used to determine the cumulants from Eq. 13 if the proper weighting of the data points is used in the curve-fitting procedure [KOPPEL, CHU]. Alternatively, the nonlinear form of Eq. 13 can be used without affecting the relative weighting of the experimental data [CHU]:

$$
(G(\tau)-G(\infty))=C_{0} \exp \left[2\left(-\bar{\Gamma} \tau+\frac{1}{2 !} \mu_{2} \tau^{2}-\frac{1}{3 !} \mu_{3} \tau^{3}+\ldots\right)\right]
$$

The first cumulant, $\bar{\Gamma}$, provides a value for the z-average (scattering-Intensity weighted average) diffusion coefficient [PHILLIES]. Strictly speaking, the cumulants are related to the moments of the distribution of the decay rates, not the moments of the 
particle size distribution [FORD, KOPPEL]. However, recovering $\overline{\mathrm{D}}$ from $\bar{\Gamma}$ involves a linear transformation in the distribution of $\Gamma$ and therefore does not alter the shape of the distribution. Consequently, the variance of $\bar{D}$ can be obtained from

$$
\frac{\mu_{2}}{q}=(D-D)^{2}
$$

If the particles being studied are noninteracting spheres, then the StokesEinstein equation may be used to estimate an average particle diameter from $\bar{D}$. For nonspherical particles such as ridgid ellipsolds, the Perrin correction factors may be used to estimate the major and minor axes. Strictly speaking, the cumulants method enables estimates of the mean particle size and the varlance to be made. It provides no information regarding the distribution function. Nevertheless, at least one manufacturer of light scattering equipment (e.g., Malvern) provides software that generates particle size distributions using the cumulants method. In the analysis, is is assumed that $G(\Gamma)$ is described by a log normal distribution. More complex analysis techniques are avallable that do provide information about the distribution [STOCK].

Our light scattering measurements are done using a Malvern $4700 \mathrm{c}$, photon correlation spectrometer (Malvern Instruments, Southborough, MA). The system is currently fitted with a Siemens, 35-mW HeNe laser (Siemens Components, Inc., Iselin, $\mathrm{NJ}$ ) and is mounted on a 4- $\mathrm{x}$ 8- $\times$ 0.67-ft (1.22- x 2.44- $\times 0.20-\mathrm{m})$ optical table (Technical Manufacturing Corp., Peabody, MA) with an overhead enclosure. The enclosure permits the optical table to be kept under a slight positive pressure using filtered air. We use a number of cylindrical glass cells having workable sample volumes as low as $300 \mu \mathrm{L}$ to as large as $20 \mathrm{~mL}$ for light scattering measurements. Special cell holders that were designed for each of the different cell sizes are shown below in Fig. 11. Each of the cells that we use have tight-fitting caps, which makes them acceptable for handling radioactive samples.

Since dynamic light scattering measurements are greatly affected by dust and other contaminants, stringent cleaning practices were employed. All glassware was cleaned by the following procedure. Initially, an alcoholic potassium hydroxide solution was used to rinse the glassware [SHUGAR], followed by a thorough rinsing with distilled water. All glassware was then rinsed with $0.1 \mathrm{M} \mathrm{HCl}$, followed by another thorough rinsing with distilled water. The glassware was coplously rinsed with fourtimes-filtered $(0.22 \mathrm{~mm})$ distilled water and placed in a sonicator for several minutes. Finally, the glassware was rinsed with four-times-filtered water. 


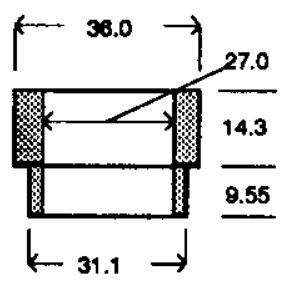

(a)

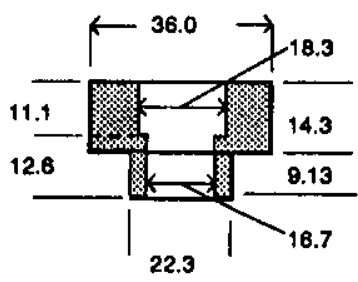

(b)

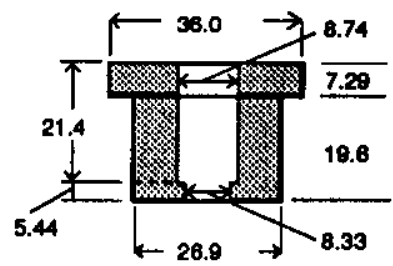

(c)

Fig. 11. Schematic Diagram of Cell Holders for (a) 1-mL, (b) 7-mL, and (c) 20-mL Sample Cells. All dimensions are given in $\mathrm{mm}$.

For samples of fairly large particles (>30 nm) that scatter well, the automeasure mode of the Malvern instrument can be used to obtain particle size without the involvement of the operator except to initlate the measurement. For particles that are less than about $30 \mathrm{~nm}$, or samples that do not scatter well, we have found that the automeasure mode can not be trusted to produce reliable results. In this situation it is best to operate the instrument manually. This requires the operator to specify the fundamental sampling time and the total data accumulation time. With very weakly scattering samples, we have used data accumulation times of up to $22 \mathrm{~h}$. General guide lines on experimental techniques in dynamic light scattering can be found in Chu's monograph [CHU] and in the paper by Phillies [PHILLIES].

Polystyrene latex beads [Duke Scientific Corp., Palo Alto, CA] of various diameters (e.g., 300,630, and $3000 \AA$ ) were used initially to evaluate the performance of the instrument. Dynamic light scattering measurements of the latex beads exhibited narrow size distributions that were in excellent agreement with the manufacturer's specifications.

In addition to the polystyrene beads, we also used puriffed bovine serium albumin (BSA) and cytochrome $c$ as particle size standards. For our measurements, we used protein solutions that were prepared following the procedure reported by Nicolli et al. [NICOLI], except that we used protein concentrations of $5 \mathrm{mg} / \mathrm{mL}$ instead of $4 \mathrm{mg} / \mathrm{mL}$. The average hydrodynamic radius $\left(\mathrm{R}_{\mathrm{H}}\right)$ obtained from light scattering measurements for BSA was $4.3 \mathrm{~nm}$, which compares quite favorably to the value of 4.4 $\mathrm{nm}$ reported by [NICOL]]. The net autocorrelation function, shown in Fig. 12, was obtained by collecting scattering data over a $10 \mathrm{~min}$. perfod using a fundimental sampling time of

$2 \mu \mathrm{s}$. Our light scattering measurements provided an average, translational diffusion coefficient for BSA of $5.7 \times 10^{-7} \mathrm{~cm}^{2} \mathrm{~s}^{-1}$. This is slightly less than the accepted value of $6.0 \times 10^{-9} \mathrm{~cm}^{2} \mathrm{~s}^{-1}$ reported in the literature for monomeric BSA [RAJ, GAIGALAS]. The monomer was obtained by gel fltration [RAJ]. Although the variance, $\mu_{2} / \bar{\Gamma}^{2}$, was fairly low (i. e., 0.10), the sample undoubtedly contained a small percentage of BSA aggregrates which would cause a reduction in the average diffusion coefficient. Unfortunately, the cumulants analysis can not be expected to resolve the particle size of the aggregrate population. 


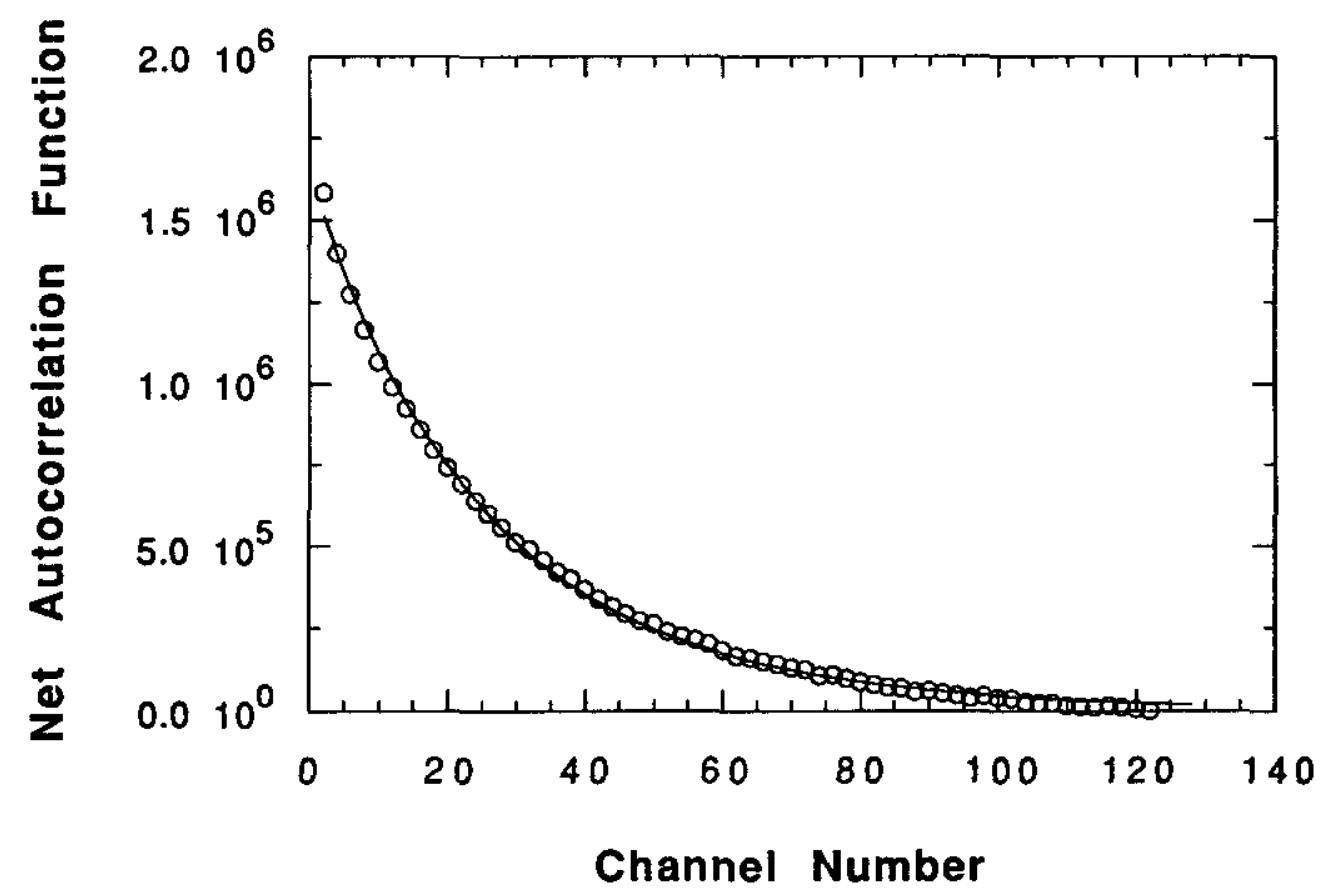

Fig. 12. Plot of the Net Autocorrelation Function for $B S A$ at $25^{\circ} \mathrm{C}$. The continueous line represents a $2^{\text {nd }}$ order cumulants fit to the data.

The smallest standard that we examined to date is cytochrome $\mathrm{c}$. This protein has a molecular weight of about 12,400 and a reported hydrodynamic radius $\left(R_{H}\right)$ of 14.2A [NICOLI, TREWHELLA]. Additionally, the diffusion coefficient of monomeric cytochrome $c$ has been determined by sedimentation and is reported to be $1.30 \times 10^{-6}$ $\mathrm{cm}^{2} \mathrm{~s}^{-1}$ [MARGOLIASH].

The preparation of our sample involved filtering it four times through a $0.2 \mu \mathrm{m}$ filter with the filtrate from the last filtration going directly into the cuvette. Because of the extremely weak intensity of the scattered light, the measurement required a collection time of approximately $22 \mathrm{~h}$. Even with such a long experiment duration, there was still a considerable amount of noise in the autocorrelation function. This is shown in Fig. 13 where the net autocorrelation function is plotted together with the fit of the data by the cumulants analysis. A fundamental sample time of $1.2 \mu \mathrm{s}$ was used. 


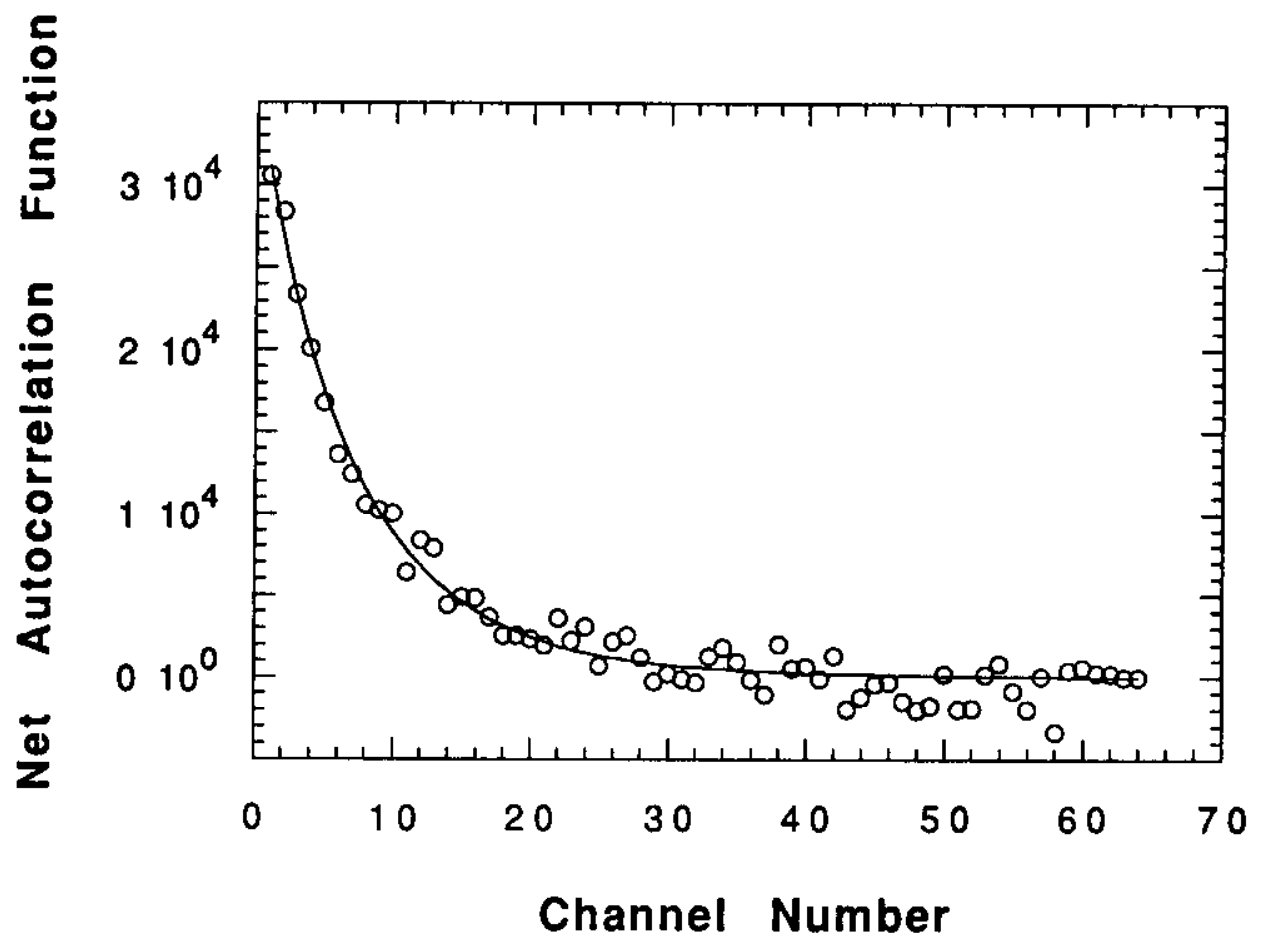

Fig. 13. Plot of the Net Autocorrelation Function for Cytochrome c at $25^{\circ} \mathrm{C}$. The continueous line represents a $2^{\text {nd }}$ order cumulants fit to the data.

Even with all the noise in the autocorrelation data, a value of $1.42 \mathrm{~nm}$ for $\mathbf{R}_{\mathbf{H}}$ was obtained, which is the literature value. A variance $\left(\mu_{2} / \bar{\Gamma}^{2}\right)$ of 0.068 indicates that the cumulants analysis should be fairly reliable. The average diffusion coefficient that we measured for cytochrome $c$ was $1.72 \times 10^{-6} \mathrm{~cm}^{2} \mathrm{sec}^{-1}$, which is about $30 \%$ larger than the value of 1.30 a $10^{-6} \mathrm{~cm}^{2} \mathrm{~s}^{-1}$ determined by sedimentation at $22^{\circ} \mathrm{C}$ [MARGOLIASH].

In choosing particle size standards, we attempted to bracket the expected size of the Pu-polymer that we are using in our partitioning studies. Not only does the size of the Pu-polymer push the limits of the light scattering technique, but the adsorption of light by the Pu-polymer throughout the entire vistble range, coupled with the inherent instability of colloidal Pu, makes these systems especially challenging to study.

This became immediately apparant during sample preparation for light scattering measurements. To remove any dust, approximately $300 \mu \mathrm{L}$ of our Pupolymer solution $\left(6.8 \mathrm{mM} \mathrm{Pu}\right.$ in $0.5 \mathrm{M} \mathrm{HNO}_{3}$ ) was filtered through a nylon membrane with a $0.45-\mu \mathrm{m}$ cut-off size. The solution filtered easily, and the clear filtrate retained its characteristic bright-green color. But after a few minutes, the filtrate rapidly turned cloudy, and a white precipitate appeared. A second filtration produced a clear, colorless filtrate, while the membrane had retained a significant portion of the collotdal Pu. This type of instability after filtration is not unique to the Pu-polymer solutions studies here. It has also been observed with other types of colloidal species in the nanometer size range [WILCOXON]. Quite often, the membranes are coated with a surfactant by the manufacturer to ald filtration. This will undoubtedly lead to 
problems, but colloid instability can also occur even if the membranes have been thoroughly washed before use [WILCOXON]. It would appear that in general, filtration is probably not an advisable way of removing large contaminant particles from colloidal suspensions.

To try to recover as much of the plutonlum from the filter as possible, we rinsed It with $0.5 \mathrm{~mL}$ of $8 \mathrm{M} \mathrm{HNO}_{3}$. This gave a light green supernatant, which we used to make dynamic light scattering measurements. At an angle of $90^{\circ}$, the scattered light count rate was only about $10^{3}$ counts-per-second (cps) and would have required an excesstvely long counting time.

In another attempt to obtain dynamic light scattering measurements of polymeric $\mathrm{Pu}$, we prepared a more concentrated $\mathrm{Pu}$-polymer solution and centrifuged the same sample (4000 rpm for $15 \mathrm{~min}$.) to remove any possible dust contaminant particles. In this case, the polymer solution was prepared by diluting the stock solution (0.09 M Pu, pH 0.99) 1:15 with $0.05 \mathrm{M} \mathrm{HNO}_{3}$. Dynamic light scattering measurements were carried out using a fundemental sample time of $5 \mu \mathrm{s}$ and an accumulation time of $6 \mathrm{~h}$. The net autocorrelation function and the cumulants fit of the data are shown in Fig. 14. In this case, the third-order cumulants method was required to provide a good fit to the data. This gave a variance in $\Gamma$ of 0.33 which is at the upper limit of applicability for the cumulants method. An average diffusion coefficient of $8.22 \times 10^{-7}$ $\mathrm{cm}^{2} \mathrm{~s}^{-1}$ was obtained and corresponds to a hydrodynamic radius of $29.8 \AA$. This diameter is simllar to the value obtained from SANS measurements carried out a year earlier [THIYAGARAJAN]. The SANS data indicated that the Pu-polymer was ellipsoidal with a major semiaxis, a, of $60 \AA$ and a minor semiaxis, b, of $11 \AA$. An equilivant spherical radius can be estimated from the SANS data using the following geometric relationship [VAN DE SANDE]:

$$
\left.\mathrm{R}_{\mathrm{H}}=\mathrm{Q} / \mathrm{h} /(\mathrm{a}+\mathrm{Q}) / \mathrm{b}\right)
$$

where $Q=\left(a^{2}-b^{2}\right)^{1 / 2}$. Using Eq. 16 , a hydrodynamic radius of $25 \dot{A}$ is obtained from the SANS measurements. This is fairly close to our value of $29.8 \AA$ and suggests a high degree of collold stability considering that this particular polymer sample was prepared in 1988 [DIAMOND].

A number of factors can adversly affect the quality of light scattering data in Pupolymer systems, such as dust contamination, abrupt changes in $\mathrm{H}^{+}$concentration (leading to colloidal instability), and localized thermal fluctuations within the beam path as the solution absorbs the laser radiation. To minimize these problems in the future, we plan to increase the sample centrifugation time to 6-7 $\mathrm{h}$ to better remove dust contamination and to reduce the beam pathlength even farther by using rectangular 1-x 10-mm cells. With our current experimental set-up, approximately $14 \%$ of the incident light energy was absorbed by the Pu sample. With a l-mm pathlength, this can be reduced to about $2.5 \%$. Unfortunately, changing to a different laser is not a viable option. In fact, adsorption at all the major wave lines produced by an argon-ion laser is even higher than it is at $633 \mathrm{~nm}$ The only laser providing a useable line that would not be adsorbed by the Pu polymer is the Nd:YAG laser. It has a major output line at $1319 \mathrm{~nm}$; however, detectors with adaquate sensitivity at this wavelength have response times that are too slow for dynamic light scattering measurements. 


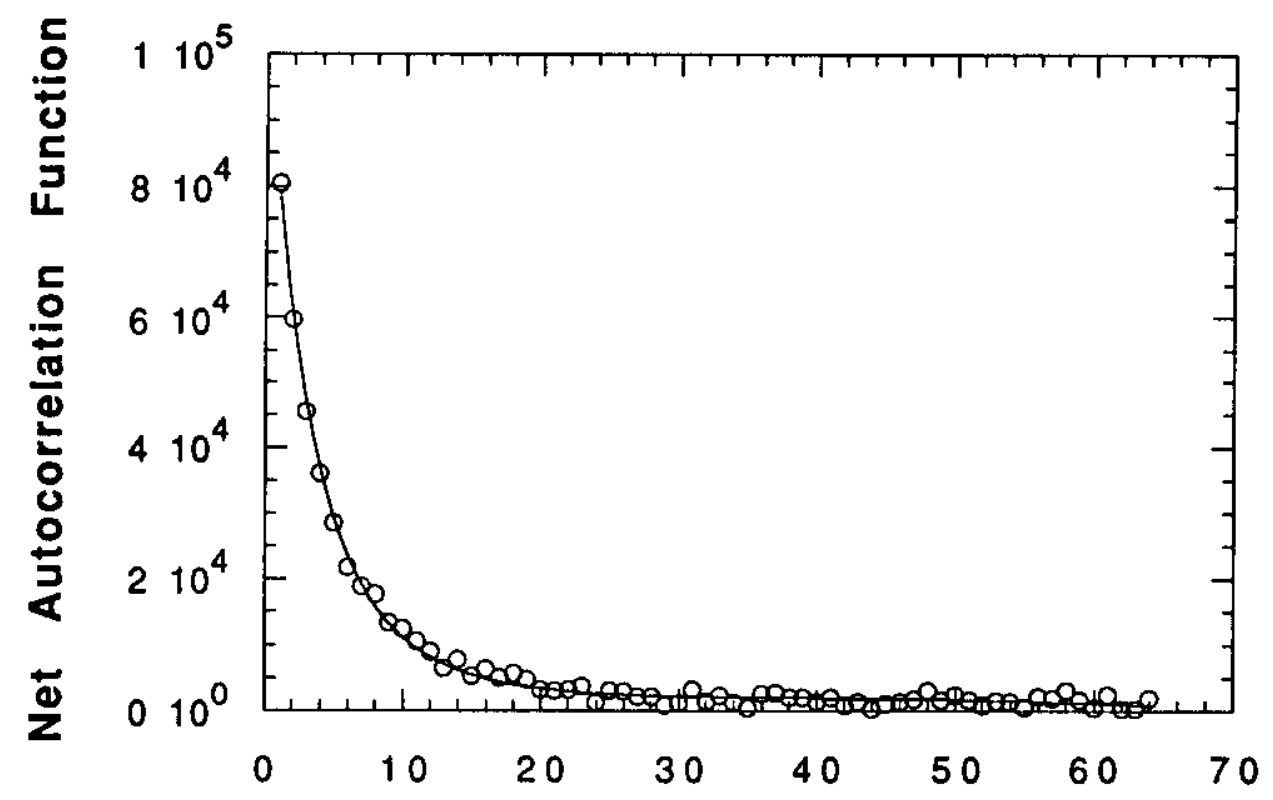

\section{Channel Number}

Fig. 14. Plot of the Net Autocorrelation Function for Pu-polymer at $25^{\circ} \mathrm{C}$. The continueous line represents a $3^{\text {rd }}$ order cumulants fit to the data.

\section{F. Qrganic Partitioning}

As in conventional oll-water solvent extraction systems, complexants can be used to selectively partition metal ions in aqueous biphase systems. However, since both phases are aqueous, both the complexants and their metal complexes must be water soluble. Complexants can also be used as phase transfer agents to promote the selective partitioning of colloidal species between immiscible aqueous phases.

Adsorption of the phase transfer agent onto a particle surface can be used to render the surface slightly hydrophobic, thus, increasing the driving force for partitioning into the PEG layer. Certain defence wastes contain mixtures of metal oxddes from which we would like to selectively recover only the actinide-bearing particles. The use of phase transfer agents is one way of assuring the selective partitioning of $\mathrm{PuO}_{2}$ in aqueous biphase systems. In an effort to gain a better understanding of the factors influencing complexant partitioning in aqueous biphasic systems, we have begun to assemble a data base of partition coefficients for water-soluble metal complexants. This represents a first step toward the goal of designing phase transfer agents for the selective extraction of actinides from mixtures of metal oxides. The results of this initial survey are reported in this section.

The partition coefficients and structures for a number of water-soluble metal complexants are shown in Table 3 and Fig. 15, respectively. The partition coefficients 
reported in Table 3 are approximations that are based on visual estimates of the color Intensity of the two aqueous phases. For complexants with $D$ values greater than 100 , there was no detectable color in the bottom salt-phase. From the list of complexants in Table 3, it is clear that neutral, cationic, and anionic aromatic spectes are extracted by PEG or PPG phases. Another chelator that we have found whose metal complexes are also extracted into PEG and PPG phases is 2,3-dihydroxynaphthalene-6-sulfonic acid. This complexant was not included in Table 3 because it is colorless in the absence of complexable metal tons. There were several complexants that, in the presence of $\mathrm{Fe}^{3+}$, had D values in the range of 0.5 to 1.0. These were tiron, pyrogallol, rhodotorulic acid. desferrioxamine $\mathrm{B}$, and 1,5-naphthalenedisulfonic acid.

Interestingly, naturally occurring organics such as the humic acids will partition between immiscible aqueous phases. Aqueous two-phase systems comprised of dextran-PEG mixtures have been used to fractionate humic acids [LINDQVIST]. This separation takes advantage of subtle differences in the surface chemical properties of these complex colloidal species.

Because humic acids are good chelators and are naturally occurring materials, we decided that they might have applications as phase transfer agents by promoting the selective partitioning of colloidal metal oxide particles in aqueous biphasic extraction systems. First, we looked at the partitioning of humic acids within aqueous biphase systems.

In the 7.5\% $\mathrm{Na}_{2} \mathrm{SO}_{4} / 15 \% \mathrm{PEG}-3400$ system, $0.02 \mathrm{wt} \%$ humic acid partitions into the PEG-phase with a D value $>100$. In this system, the top phase is an opaque black while the bottom phase is colorless. The addition of up to $1 \% \mathrm{Al}\left(\mathrm{NO}_{3}\right)_{3}$ had no effect on the partitioning of humic acid in this system. However, in the $22.5 \%$ $\mathrm{NaNO}_{3} / 25 \%$ PPG system, the humic acid partitioned into the bottom $\left(\mathrm{NaNO}_{3}\right)$ phase with a $\mathrm{D}$ value $<1$. But when $1 \% \mathrm{Al}\left(\mathrm{NO}_{3}\right)_{3}$ is added to the system, the humic acid is transferred to the top (PPG) phase with a $\mathrm{D}$ value $>100$. It is well known that $\mathrm{H}^{+}$and polyvalent cations can adsorb onto ion exchange sites of humic acids, thereby causing the molecule to fold in on itself, and expose hydrophobic regions on the collold surface [BOLT]. This seems to explain the effect of $\mathrm{Al}^{3+}$ on the partitioning of humic acid in the PPG system.

The aqueous phases can be qualitatively ranked on the basis of increasing hydrophobicity as follows: $\mathrm{Na}_{2} \mathrm{SO}_{4}, \mathrm{NaNO}_{3}<$ PEG < PPG. While conformational changes in humic collolds affect their partitioning behavior in the PPG system, they surprisingly do not appear to have any influence on partitioning in the PEG system. This suggests that the interaction between PEG and humic colloids is quite strong and that PEG can bring about the same type of conformational changes that are induced by polyvalent cations. We would like to follow-up the partitioning studies with laser light scattering measurements of particle size and shape and to try and correlate partitioning behavior with this type of structural information.

The complexation of Pu(IV) and hydrous, polymeric Pu(IV) by humic acid and its potential use as a phase transfer agent in aqueous biphasic extraction systems was also examined. These results are discussed below in Section I. 
We believe that partitioning studies in conjunction with laser light scattering measurements could form the basis of new and sensitive techniques to probe the surface chemical properties and overall conformational structure of humic and fluvic acids. Their well-known metal complexing abilities make these organic collofds important actors in metal ion transport through subsurface environmental systems.

Table 3. Partition Coefficients for Several Water Soluble Metal Complexants Name Solvent Composition Partition Coefficient

\begin{tabular}{|c|c|c|}
\hline Brilliant Green & $\begin{array}{l}15 \%\left(\mathrm{NH}_{4}\right)_{2} \mathrm{SO}_{4} / \\
15 \% \text { PEG }-3400 \\
\text { pH4 }\end{array}$ & $>100$ \\
\hline Crystal Violet & & $>100$ \\
\hline Xylenol Orange & & -10 \\
\hline Tolutdine Blue $\mathrm{O}$ & & $\sim 10$ \\
\hline Arsenazo I & & $>100$ \\
\hline Arsenazo III & & $>100$ \\
\hline Methylthymol Blue & & $>100$ \\
\hline Sulfonazo III & $\begin{array}{l}7.5 \% \mathrm{Na}_{2} \mathrm{SO}_{4} / \\
15 \% \mathrm{PEG}-3400\end{array}$ & $>100$ \\
\hline Pyrocatechol Violet & & $\sim 10$ \\
\hline PAN & & -10 \\
\hline PAR & & $\sim 10$ \\
\hline Rhodamine B & & $\sim 10$ \\
\hline Rhodamine B & $\begin{array}{l}7.5 \% \mathrm{Al}_{2}\left(\mathrm{SO}_{4}\right)_{3} / \\
15 \% \mathrm{PEG}-3400\end{array}$ & $>100$ \\
\hline
\end{tabular}




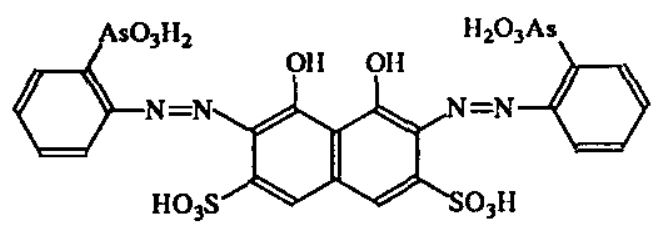

Arsenazo III<smiles>CCN(CC)c1ccc(C(=C2C=CC(=[N+](C)CC)C=C2)c2ccccc2)cc1</smiles>

Brilltant Green<smiles>CC1=CC(=C(c2cc(Cl)c(O)c(COC(=O)O[Na])c2)c2ccccc2[N+](=O)[O-])C=C(CCN(C)C(=O)O[Na])C1=O</smiles>

Xylenol Orange<smiles>Oc1ccc(N=Nc2ccccn2)c(O)c1</smiles>

PAR<smiles>O=S(=O)(O)c1cc(O)c2c(O)c(N=Nc3ccccc3S(=O)(=O)O)c(S(=O)(=O)O)cc2c1</smiles>

Arsenazo 1<smiles>CS(=O)(=O)c1ccccc1N=Nc1c(S(=O)(=O)O)cc2cc(S(=O)(=O)O)c(N=Nc3ccccc3S(=O)(=O)O)c(O)c2c1O</smiles>

Sulfonazo III<smiles>CC1=C(CCN(CC(=O)O[Na])C(=O)O[Na])C(=C(c2ccccc2[N+](=O)[O-])c2ccccc2[N+](=O)[O-])C=C(C(C)C)C1=O</smiles>

Methylthymol Blue<smiles>Cc1cc2nc3ccc(=[N+](C)C)cc-3sc2cc1N</smiles>

Toluidine Blue $O$

Fig. 15. Structural Formulas of Water-Soluble Complexants 
<smiles></smiles>

Rhodamine B<smiles>Oc1ccc2ccccc2c1N=Nc1ccccn1</smiles>

PAN<smiles>CN(C)c1ccc(C(=C2C=CC(=[N+](C)C)C=C2)c2ccc(N(C)C)cc2)cc1</smiles>

Crystal Vlolet<smiles>O=C1C=CC(=C(c2ccc(O)c(O)c2)c2ccccc2S(=O)(=O)O)C=C1O</smiles>

Pyrocatechol Vlolet

Fig. 15. (Contd)

Several of the complexants found in Table 3 can be added to the list of watersoluble metallochromic indicators known to partition preferentially into the PEGphase from aqueous salt solutions [ZAROVA]. In general, it appears that sulfonated aromatic compounds are extracted into PEG and PPG phases particularly well. In an earlier study, we found that sulfonated nitrotoluenes could be extracted from aqueous sodium sulfate/sodium nitrate solutions by a PEG-phase [CHAIKO-1989]. The types of organic molecules that show high affinities for the PEG phase are amphiphilic. That is, they contain both hydrophilic and hydrophobic moleties within the molecule. However, the types of molecules showing high affinities for the PEG-phase tend to be structurally more akin to hydrotropes such as benzene sulfonates [ELWORTHY] than to the classic surfactants like sodium dodecyl sulfate.

We are currently attempting to grow crystals of complexes formed between low molecular weight PEG/PPG and the chelators in an effort to identify, by single crystal $X$-ray diffraction, the bonding mechanism responsible for the near quantitative extraction. 


\section{G. Sllica Partitioning}

A major constituent of incinerator ash and ash heels is silica. In that respect, the recovery of plutonlum from these residues depends upon the ability to make efficient separations between $\mathrm{PuO}_{2}$ and various types of silicates. Therefore, we need a firm understanding of the partition behavior of silica in aqueous biphase systems. In this section, we summarize the results of silica partition studies.

The partitioning behavior of stlica is highly dependent upon $\mathrm{pH}$ and is directly related to the ionization of surface $\mathrm{SIOH}$ groups. Previous studies by others have shown that only uncharged silanol groups can form hydrogen bonds with electron donor groups like ethylene oxide [ILER-1979A]. Between the pHs of about 1.5 and 3.5, silica carries a low surface charge density [ILER-1979A]. It is in this same pH region that we have observed the maximum silica partition coefficients in the PEG/sodium sulfate system.

When PEG adsorbs onto a silica surface, the oxygen atoms must be oriented toward the $\mathrm{SiOH}$ surface in order to hydrogen bond to it. At the same time, the hydrocarbon groups can become orlented outward, away from the sllica surface. The hydrophobic surface regions generated by this preferential orientation thus promote the partitioning of silica into the PEG phase. In going from a pH of about 2 to about 4 . there is only a slight increase in the silica surface charge, but at $\mathrm{pH} \geq 5$ the surface charge becomes increasingly negative much more rapidly [ILER-1979A]. As the pH is raised, counter-cation adsorption at the silica surface increases in proportion to surface charge. Because of the relatively large size of hydrated cations such as $\mathrm{Na}\left(\mathrm{H}_{2} \mathrm{O}_{6}^{+}\right.$, surface ionization is also thought to prevent polymer adsorption to neutral silanol groups that are in the immediate vicinity of $\mathrm{SiO}^{-}$surface sites [ILER-1979A].

Anionic surface sites can also be generated in silica by the substitution of the 4coordinate aluminate ion, $\mathrm{Al}(\mathrm{OH})_{4}{ }^{-1}$, for $\mathrm{Si}(\mathrm{OH})_{4}$, thus creating an aluminosilicate site with a fixed negative charge [ILER-1979B]. Aluminate is easily inserted or exchanged onto silica because the anion is geometrically similar to $\mathrm{Si}(\mathrm{OH})_{4}$ and is about the same size. Hydrogen bonded complexes reportedly do not form with colloidal aluminosilicates, such as clays or zeolites, unless the aluminum is first extracted from the surface with acid or the mineral surface is first coated with a film of silica [ILER-1979A].

At a pH of 3 to 3.5 in the $7.5 \% \mathrm{Na}_{2} \mathrm{SO}_{4} / 15 \%$ PEG-3400 system, we have observed partition coefficients $>10^{2}$ for ground silica gel, submicron glass beads, 20 -nm colloidal silica, and various clays. In some of these tests, the solids concentration was as high as $2 \mathrm{wt} \%$, giving partition coefficients in excess of $10^{3}$. In every case, the silica partitioned into the PEG phase, leaving the bottom sulfate phase with no trace of cloudiness. The particle size distribution of the ground sllica and the glass beads was between 0.1 and $1.0 \mu \mathrm{m}$, as determined by light scattering. Samples for light scattering measurements were prepared as $10^{-4}$ wt \% suspensions in water. Suspensions at this solids concentration appeared slightly cloudy due to multiple light scattering effects. Since the sulfate phases were clear, the silica concentration in those phases can be estimated as less than $10^{-4} \mathrm{wt} \%$. 
Partition measurements were performed with two different types of clay. kaolinite and montmorllonite, both of which have a layered structure. Kaolinite is made up of alternating layers of silica tetrahedra and gibbsite, $\mathrm{Al}(\mathrm{OH})_{3}$, with siloxane and gibbsite on the upper and lower basal planes, respectively, and silanol and aluminol groups on the edge faces [GREENLAND]. The stloxane surface has a very low or zero charge and is hydrophobic, while the edge faces carry a pH-dependent charge due to the ionization of silanol and aluminol groups [GREENLAND]:

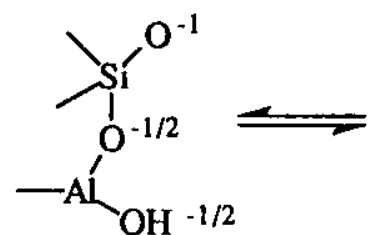

Basic pH

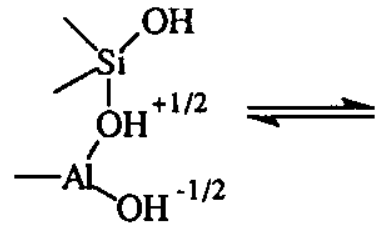

Neutral pH

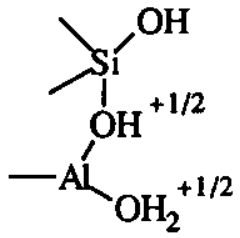

Acid pH

In the montmorillonite structure, two layers of sllica tetrahedra are condensed with gibbsite, with silica tetrahedra superimposed on both sides of the gibbsite layer. Substitution of octahedral $\mathrm{Al}^{3+}$ by $\mathrm{Mg}^{2+}$ and $\mathrm{Fe}^{3+}$ and substitution of tetrahedral $\mathrm{Si}^{4+}$ by $\mathrm{Al}^{3+}$ gives rise to a negative layer charge. Electroneutrality is maintained by the free exchange of hydrated cations between the silica layers [BROWN]. A variety of uncharged polar organic compounds form complexes with montmorillonite. Low molecular weight polyethylene glycols, for example, form complexes with the exchangeable cations $\mathrm{Mg}^{2+}$ and $\mathrm{Ca}^{2+}$ by hydrogen bonding to the cationic hydration shell [BROWN].

Partition measurements have shown that silica is extracted by PEG at pHs near the isoelectric point, but no detectable extraction occurres at $\mathrm{pH} 6$. On the other hand, kaolinite and montmorillonite are both extracted equally well by the PEG phase at pHs 3,6 , and 12. We believe that the reason for this is that the PEG interacts with the basal siloxane surface only through weak hydrophobic bonding, which would be expected to be independent of $\mathrm{pH}$. The surface axygen atoms in the basal surfaces of montmorillonite and kaolinite are fully coordinated and are weak electron donors [RAUSELL-COLOM]. As such, the siloxane oxygens are not able to hydrogen bond directly to the oxygens in PEG. Another possible mode of interaction between montmorlllonite and PEG is through hydrogen bond formation with exchangeable cations located in interstitial planes and near the edge face of the clay particle.

For both montmorllonite and kaolinite, sllanol groups occur only at edge surfaces. Adsorption of PEG through hydrogen bonding to these edge groups would show the same $\mathrm{pH}$ dependance as on silica. However, since the edge area is only about $1 \%$ of the basal surface area [TAYLOR], this mode of bonding is probably insignificant.

A slight $\mathrm{pH}$ dependance on the extraction of silicic acid was observed, which mirrors that observed with colloidal silica. The partitioning of silicic acid was measured using a ${ }^{32} \mathrm{~S} 1$ radiotracer. ${ }^{32} \mathrm{Si}(1 \mu \mathrm{Ci})$ was purchased from Los Alamos National Lab as $\mathrm{Si}(\mathrm{IV})$ in $0.1 \mathrm{M} \mathrm{NaOH}$. The stock solution was stored in a screw-capped Teflon container. The partitioning of Si(IV) in $7.5 \% \mathrm{Na}_{2} \mathrm{SO}_{4} / 7 \%$ PEG was measured by splking the biphase system with the radiotracer and then analyzing the PEG and sulfate 
phases for beta activity by liquid scintillation counting. At pHs of 3 and 6 , the partition coefficients of Si(IV) were 0.64 and 0.38 , respectively, and the predominant silica species was monosilicic acid $\left(\mathrm{Si}(\mathrm{OH})_{4}\right)$, with the first ionization product $\left(\mathrm{SiO}(\mathrm{OH})^{3}\right.$ ) not becoming important until the $\mathrm{pH}$ was 9 [ILER-1979C]. The ${ }^{32} \mathrm{Si}$ stock solution was approximately $1.5 \mu \mathrm{M}$ and in the biphase system, the SI concentration was approximately $7.3 \times 10^{-9} \mathrm{M}$. Because of the extremely low silica concentrations, both in the stock solution and the biphase system, the formation of polysilicic acids and colloidal Si is considered to be negligible. Monomeric sllicic acid is known to be stable in water at $25^{\circ} \mathrm{C}$ provided its concentration is less than about $1 \mathrm{mM}$ [ILER-1979C].

The difference in $\mathrm{D}$ values between silicic acid and colloidal silica is quite large and reflects the large bonding energy between the sillica and PEG. In the case of colloidal silica, PEG can attach to the particle surface through hydrogen bonding at numerous points along the PEG chain. While the bonding energy is fairly low at any one point, the overall adsorption energy becomes quite large when multiplied by the total number of contact points. With silicic acid, there are a total of four possible hydrogen bond locations per molecule. However, if the PEG molecule is in a linear conformation, then only one bond between SI(OH) 4 and PEG is possible. Since silicic acid is in competition with water for these bonding sites on the PEG molecule, the equilibrium is shifted in favor of the more abundant water. The $D$ value for sllicic acid is not much larger than that for sulfate which, as discussed above, was found to be $\mathbf{0 . 2 4}$ at $\mathrm{pH} 6$.

From the studles completed to date, we have a fairly good understanding of the partitioning behavior of sllica and clay minerals. On a mechanistic level, however. more needs to be known about the basis for the strong interactions between PEG and the clay minerals. This type of information would ald in the design of aqueous biphasic processes for treating contaminated solls.

\section{H. Silica/Metal Oxide Separations}

The abllity to quantitatively separate silica from a wide range of metal oxides is a particularly attractive feature of aqueous biphasic extraction. For example, in preliminary separations that we carried out using nonradioactive materials, micronsize, amorphous $\mathrm{SiO}_{2}$ particles were quantitatively recovered from mixtures of metal oxides such as hematite $\left(\mathrm{Fe}_{2} \mathrm{O}_{3}\right)$ and rutile $\left(\mathrm{TiO}_{2}\right)$. With a biphase system consisting of $15 \%$ PEG-3400/7.5\% $\mathrm{Na}_{2} \mathrm{SO}_{4}$ at a pH of 3 , greater than $99.99 \%$ of the metal oxide particles partitioned to the bottom $\left(\mathrm{Na}_{2} \mathrm{SO}_{4}\right)$ phase. while greater than $99.99 \%$ of the $\mathrm{SiO}_{2}$ particles partitioned to the top (PEG) phase. This is an effective, single-stage separation factor $>10^{8}$. The solids concentration in the respective phases was $2 \mathrm{wt} \%$.

This partitioning behavior is based on surface chemical properties and not on bulk phase properties like density. Consequently, those factors that influence surface characteristics can, in principle, be used to selectively control partitioning behavior. Many of the same chemical reagents used in mineral flotation to promote or suppress particle attachment at the air/water interface can be used in aqueous biphasic systems for promoting separations between metal oxides, and silicates [ANANTHAPADMANABHAN-1987A]. Some examples of surface-modified phase transfer in aqueous biphase systems are listed in Table 4. 
Table 4. Surface-Modifled Phase Transfer in Aqueous Biphasic Extractiona

\begin{tabular}{llc}
\hline Solid & Reagent & Partition Coefficient \\
\hline $\mathrm{TiO}_{2}, \mathrm{Fe}_{2} \mathrm{O}_{3}, \mathrm{Al}_{2} \mathrm{O}_{3}$ & None & $<0.0001$ \\
$\mathrm{TiO}_{2}, \mathrm{Fe}_{2} \mathrm{O}_{3}, \mathrm{Al}_{2} \mathrm{O}_{3}$ & $0.1 \%$ Sodium Silicate, $\mathrm{pH} 3$ & $>200$ \\
$\mathrm{Fe}_{2} \mathrm{O}_{3}, \mathrm{THO}_{2}, \mathrm{Al}_{2} \mathrm{O}_{3}$ & $0.01 \%$ Oleic Acid & $>200$ \\
$\mathrm{CaCO}_{3}$ & None & $<0.005$ \\
$\mathrm{CaCO}_{3}$ & $0.01 \%$ Oleic Acid & $>200$ \\
\hline
\end{tabular}

a Biphase System: $15 \%$ PEG-3400/7.5\% $\mathrm{Na}_{2} \mathrm{SO}_{4}$ at a pH of 6 .

In the PEG/sodium sulfate system, the metal oxddes listed in Table 3 moved quantitatively to the sulfate-containing phase, regardless of $\mathrm{pH}$. The affinity of the metal oxddes for the sulfate phase is understandable given the fact that sulfate is known to be surface-active towards a number of metal oxides, including $\mathrm{TiO}_{2}$ and $\mathrm{Al}_{2} \mathrm{O}_{3}$ [FUERSTENAU-1970]. In general, the ionic interaction of electrolyte lons at a metal oxdde surface would be expected to inhibit the adsorption of PEG, which occurs through a much weaker hydrogen bond. In addition, PEG must compete with the water of hydration for surface adsorption sites. Measurements of the heat of immersion $\left(\Delta \mathrm{H}_{\mathrm{i}}\right)$ can give an indication of the energy of interaction between solid surfaces and the surrounding water molecules. A large exothermic heat of immersion indicates very strong adsorption of water. The partitioning of $\mathrm{SiO}_{2}$ and the metal oxides between the sodium sulfate and PEG phases can be qualitatively related to the heat of immersion. Solids having low values of $\Delta \mathrm{H}_{\mathfrak{i}}$, such as graphite and silica, partition into the PEG layer, while those solids with large $\Delta \mathrm{H}_{1}$ values, such as the metal oxides, partition into the sulfate phase. Some values of the heat of immersion are listed in Table 5.

To obtain a separation between metal oxides, selective adsorption of watersoluble surfactants onto the desired metal oxide surfaces can be used to render the solids sufficiently hydrophobic to cause them to partition into the PEG phase [ANATHAPADMANABHAN-1987A]. However, we have found that surfactants which adsorb through physical interactions, such as electrostatic attraction and hydrophobic bonding, tend to be ineffective phase transfer agents.

For example, the adsorption of sodium dodecyl sulfate (SDS) and sodium dodecyl benzene sulfonate (SDBS) onto $\mathrm{THO}_{2}, \mathrm{Al}_{2} \mathrm{O}_{3}$, and $\mathrm{Fe}_{2} \mathrm{O}_{3}$ at a pH below the Pointof-Zero-Charge (PZC) of each solid is known to take place through electrostatic attraction between the anionic surfactant and the positively charged metal oxide surface [LEJA]. In the aqueous biphase system, partition coefficients $<0.005$ were obtained with each of the metal oxides listed in Table 4, even in the presence of SDS and SDBS. Varying the SDBS concentration from $10^{-6}$ to $10^{-1}$ wt $\%$ had no effect on the 
Table 5. Partition Coefficients and Corresponding Heats of Immersion in Water ${ }^{a}$ in the Sodium Sulfate/PEG System at a $\mathrm{pH}$ of 3

\begin{tabular}{lcc}
\hline Solid & Partition Coefficient & $-\Delta \mathrm{H}_{\mathrm{i}}$, ergs $/ \mathrm{cm}^{2}$ \\
\hline Graphite & $>200$ & 26 \\
Amorphous Silica & $>200$ & $165-220$ \\
Quartz & $>200$ & $260-370$ \\
$\mathrm{Fe}_{2} \mathrm{O}_{3}$ (hematite) & $<0.005$ & 530 \\
$\mathrm{TiO}_{2}$ (rutile) & $<0.005$ & 550 \\
$\mathrm{Al}_{2} \mathrm{O}_{3}$ & $<0.005$ & $650-900$ \\
\hline
\end{tabular}

aData from [FUERSTENAU-1976].

partitioning of $0.25 \% \mathrm{TiO}_{2}$ suspensions. In the high lonic strength environment of the PEG/sodium sulfate system, the electrolyte ions, by virtue of their high concentration. are able to exclude ionic surfactants from surface adsorption sites on metal oxide surfaces. Thus, there is insufficient coverage of these sites for phase transfer to occur. The extent of surfactant exclusion from metal oxide surfaces by electrolyte ions is also a function of the water solubility of the surfactant. Highly water soluble surfactants such as SDS and SDBS are more easlly excluded from surface adsorption sites by the sulfate-phase than less water soluble surfactants such as oleic acid. This point will be discussed in more detail below.

In contrast to the poor performance of physically adsorbed collectors, we have found that surfactants which chemisorb through covalent bonding can be quite effective at promoting solids partitioning from aqueous sulfate solutions into PEG phases. As shown in Table 4, oleic acid promotes the transfer of $\mathrm{Fe}_{2} \mathrm{O}_{3}$ and $\mathrm{TiO}_{2}$ into the PEG-rich phase. The chemisorption of oleic acid onto hematite and rutile has been demonstrated by infrared spectroscopy, which shows surface hydroxyl displacement by oleate [FUERSTENAU-1970].

Although there is no evidence available in the literature to suggest that oleic acid is capable of chemisorbing onto $\mathrm{Al}_{2} \mathrm{O}_{3}$, this phase transfer agent is, never the less, capable of promoting the extraction of $\mathrm{Al}_{2} \mathrm{O}_{3}$ by the $\mathrm{PEG}$ phase. In this instance, we believe that oleic acid is physically adsorbed at the aluminum oxide surface. The pointof-zero-charge (PZC) for $\mathrm{Al}_{2} \mathrm{O}_{3}$ is known to occur at $\mathrm{pH}$ 9. Therefore, at $\mathrm{pH} 6$, the oxide surface is positively charged and promotes adsorption of anionic oleic acid molecules. The fact that $\mathrm{Al}_{2} \mathrm{O}_{3}$ partitions to the sulfate phase with a $\mathrm{D}$ value $<0.005$ at $\mathrm{pH} 12$ (ie., above the PZE) offers support to this mechanism. That is, when the $\mathrm{Al}_{2} \mathrm{O}_{3}$ surface bears a negative surface charge. charge repulsion prevents the oleic acid from attaching to the oxide surface. 
The alkyl sulfates and alkyl benzene sulfonates with $\mathrm{C}_{12}$ R-chains are significantly more water soluble than oleic acid. At high ionic strengths, the activity of the water-soluble surfactants would be adversely affected by a reduction in the critical micelle concentration (CMC). They also compete with sulfate ions for surface adsorption sites that further reduce its surface activity. This, in turn, results in reduced surface coverage of these surfactants to where they no longer can function as phase transfer agents. They are, however, effective flotation collectors because those systems are operated at very low lonic strengths.

The low water solubllity of olelc acid, on the other hand, does not permit an appreciable micelle concentration to develop in the aqueous phase. Thus, the overall free energy of the system is minimized primarily by phase separation. Electrostatic adsorption of oleic acid at the solid/liquid interface is reinforced by dispersion forces and hydrophobic bonding interactions between the $\mathrm{C}_{18}$ R-chains of adjacent surfactant molecules at the interface. For high molecular weight surfactants, these R-chain interactions are sufficiently strong for the surfactant to displace inorganic tons from solid substrates by an ion exchange mechanism [ROSEN-1989B].

As indicated in Table 4, calcite $\left(\mathrm{CaCO}_{3}\right)$ also partitions into the PEG layer when $0.01 \%$ oleic acid is added to the aqueous biphase system, which is another example of phase transfer brought about by chemisorption of the collector at the mineral surface.

Activation of insoluble oxides can be brought about by the adsorption of monosilicic acid and polysilicic acids. The addition of $0.1 \%$ sodium silicate to a particle suspension at a $\mathrm{pH} \leq 9$ was used to deposit a sllica coating on the metal axide surfaces. At a pH of 8 to 10 , mono- and polysilicic acids are rapidly adsorbed onto insoluble metal oxides via a base-catalyzed reaction [ILER-1979A] as follows:

$$
\mathrm{Me}-\mathrm{OH}+\mathrm{Si}(\mathrm{OH})_{4} \stackrel{\mathrm{OH}^{-}}{\longrightarrow} \mathrm{Me}-\mathrm{O}-\mathrm{SI}(\mathrm{OH})_{3}+\mathrm{H}_{2} \mathrm{O}
$$

When the aqueous biphase system is adjusted to a $\mathrm{pH}$ of 6 or greater, the metal oxides continue to move to the bottom phase. just as they do in the absence of sodium silicate. But when the $\mathrm{pH}$ is reduced to 3 , the metal oxddes transfer quantitatively to the top phase. This $\mathrm{pH}$ dependence parallels the partitioning behavior of ground. amorphous silica and glass, which partitions to the PEG layer at a $\mathrm{pH} \leq 3.5$ and to the sulfate layer at a $\mathrm{pH} \geq 6$.

If the $\mathrm{pH}$ is above 10 during the pre-equilibration of the metal oxddes with sodium silicate, the predominant silica species will be $\mathrm{SiO}(\mathrm{OH})_{3}{ }^{-}$and, consequently, the silica is not deposited on the metal oxide surface. When the $\mathrm{pH}$ of the biphase system is then lowered to 3 , the metal oxides will partition into the sulfate phase.

In attempting to separate metal oxides and sllicates, it is clear that precautions must be taken to prevent the metal oxides from becoming activated by dissolved silica. As outlined above, $\mathrm{pH}$ control can be an effective method of preventing silica deposition on metal oxides. When treating contaminated materials, we would like not only to separate metal oxides from silicates, but also to recover $\mathrm{PuO}_{2}$ and $\mathrm{UO}_{2}$, selectively from all other metal oxides present in the feed. To accomplish this goal, phase transfer 
agents that are selective for these particular oxides need to be identifled. In the next section, partitioning data for polymeric Pu(IV) in the presence of water-soluble chelators are presented and discussed.

\section{Plutonium Partitioning}

As with other metal oxides, polymeric Pu(IV) partitions quantitatively to the sulfate layer. In experiments carried out thus far, polymeric Pu(IV) has been used as a stand-in for particulate $\mathrm{PuO}_{2}$. Data from $\mathrm{x}$-ray diffraction measurements have shown that the plutonlum polymer has a $\mathrm{PuO}_{2}$-crystal lattice structure, while SANS measurements indicate that the polymer is approxdmately $22 \AA$ in diameter and $120 \dot{A}$ long [THIYAGARAJAN].

We have expected that the surface properties of the plutonium polymer and of ground, micron-size $\mathrm{PuO}_{2}$ particles are similar. The surfaces of both contain hydrated Pu-OH sites and should therefore take part in similar complexation reactions. Correlating the partitioning of monomertc Pu(IV), polymeric Pu(IV). and micron-size $\mathrm{PuO}_{2}$ particles is currently underway. Thus far, we have found that the partitioning behavior of monomeric and polymeric Pu(IV) is similar. Both species have low partition coefficients in the $7.5 \% \mathrm{Na}_{2} \mathrm{SO}_{4} / 15 \%$ PEG-3400 biphase system, which are about what we would expect for metal lons and colloidal metal oxides, respectively. (See Table 6.)

When metal complexing dyes such as Arsenazo I and III are introduced into the biphase system, polymeric Pu(IV) is extracted into the PEG phase. Extraction data that compare the partitioning of polymeric $\mathrm{Pu}(\mathrm{IV})$ in the presence of several extractants are given in Table 7. In the $15 \%\left(\mathrm{NH}_{4}\right)_{2} \mathrm{SO}_{4} / 15 \%$ PEG-3400 system and in the absence of any complexant, the $\mathrm{D}$ value for polymeric $\mathrm{Pu}(\mathrm{IV})$ is about 0.07 . This is approximately 70 times larger than the $\mathrm{D}$ value for polymeric $\mathrm{Pu}(\mathrm{IV})$ in the $7.5 \% \mathrm{Na}_{2} \mathrm{SO}_{4} / 15 \%$ PEG3400 biphase system. It is not known whether this difference is due to the higher ionic strength in the ammonium sulfate system or to a cation effect on biphase properties resulting from the substitution of ammonium for sodium.

Table 6. Partitioning of Monomeric and Polymeric Pu(IV) in the $7.5 \% \mathrm{Na}_{2} \mathrm{SO}_{4} / 15 \%$ PEG-3400 Biphase System at $25^{\circ} \mathrm{C}$

Pu(IV) Species $\quad$ Partition Coefricient

$\begin{array}{ll}\text { Monomeric }{ }^{238} \mathrm{Pu}(\mathrm{IV}) & 0.17 \\ \text { Polymeric }{ }^{239} \mathrm{Pu}(\mathrm{IV}) & 0.001\end{array}$


Table 7. Partitioning of Polymeric Pu(IV) in the $15 \%\left(\mathrm{NH}_{4}\right)_{2} \mathrm{SO}_{4} /$ $15 \%$ PEG-3400 Biphase System at $25^{\circ} \mathrm{C}$

\begin{tabular}{lc}
$\begin{array}{l}\text { Extractant, } \\
0.01 w t \%\end{array}$ & Partition Coefficient \\
\hline None & 0.069 \\
Arsenazo I & 1.5 \\
Arsenazo III & 621.0 \\
Sulfonazo III & 0.038 \\
\hline
\end{tabular}

The extraction of a number of trivalent and tetravalent lanthanides and actinides by PEG/ammonium sulfate biphase systems containing Arsenazo III has been reported [SHKINEV, MOLOCHNIKOVA-1987]. We were interested to see if Arsenazo III could also extract colloidal Pu(IV). As the data in Table 7 and Figs. 16 and 17 indicate, this complexant is indeed an effective phase transfer agent for colloidal Pu(IV). From a least-squares fit, the slope of the straight line in Fig. 16 is 0.55 and suggests that approximately two Pu species are complexed per Arsenazo III molecule. For proper slope analysis, Fig. 16 should be plotted in terms of activities, not concentrations. Therefore, any stoichlometric relationship derived from Fig. 16 should be interpreted with caution.

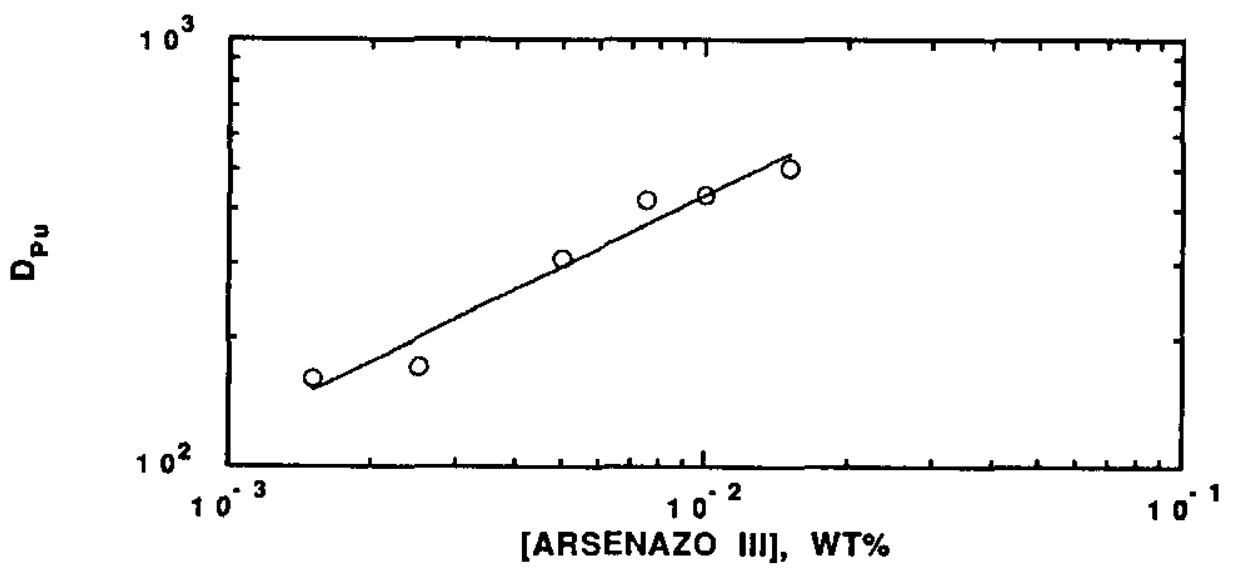

Fig. 16. Extraction of Polymeric Pu(IV) by Arsenazo III in the 15\% $\left(\mathrm{NH}_{4}\right)_{2} \mathrm{SO}_{4} / 15 \%$ PEG-3400 System at a pH of 6 and $25^{\circ} \mathrm{C}$ 


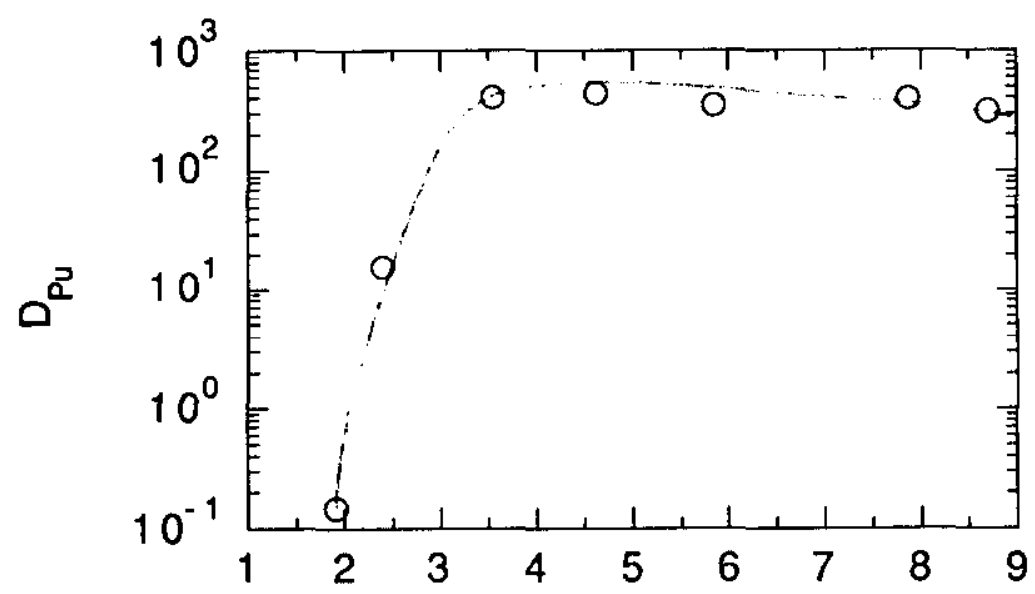

$\mathrm{pH}$

Fig. 17. Extraction of Polymeric Pu(IV) by Arsenazo III as a Function of $\mathrm{pH}$ in the $15 \%\left(\mathrm{NH}_{4}\right)_{2} \mathrm{SO}_{4} / 15 \%$ PEG-3400 System at $25^{\circ} \mathrm{C}$

Arsenazo I and III form stable complexes with $+2,+3$, and +4 cations under a variety of conditions [SAVVIN]. Arsenazo III forms 1:1 complexes with elther +2 or +3 cations and forms $1: 1$ or $1: 2$ complexes with +4 cations, depending on the metal-tocomplexant concentration ratio [MUK, SAVVIN]. The plot in Fig. 16 suggests a 2:1 complex, but this may simply be an artifact produced by stearic constraints arising from the colloid particle structure that allows only a fraction of the Pu atoms in the colloid being accessible to complexation by Arsenazo III. In addition, colloid partitioning to the PEG phase would not necessarlly require complete complexation of all $\mathrm{Pu}$ atoms that happen to reside on the particle surface.

The extractants listed in Table 7 constitute a homologous series whose structures are shown in Fig. 15. Arsenazo I contains one arsonic acid functional group. while Arsenazo III contains two of them. Both molecules contain the dihydroxydisulfonaphthylene molety. Complexation to +2 cations is reported to take place through the arsonic acid and the adjacent azo group, as shown in Fig. 18. In the Sulfonazo III molecule, sulfonic acid groups are substituted for both of the arsonic acid groups in Arsenazo III. As indicated previously in Table 3, all three complexants are extracted into the PEG phase with $D$ values $>100$. The high $D$ values are a result of the fact that the Arsenazo-type complexants are not soluble in aqueous solutions of very high lonic strength [SAVVIN]. Under these conditions, the majority of the water is tied up in the inner hydration shells of the electrolyte lons thereby leaving insufficient amounts of free water to satisfy the hydration requirements of the complexant molecules. 


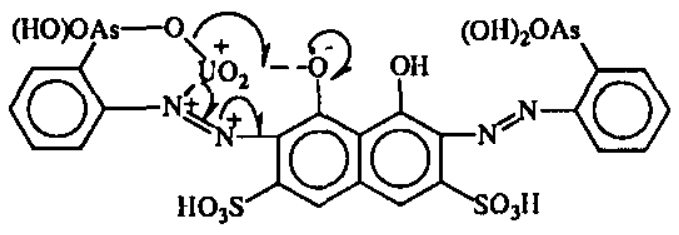

Fig. 18. Metal Complex Formation with Arsenazo III [SAVVIN]

Increasing colloidal Pu extraction in the presence of metal complexants follows this order: Arsenazo III > Arsenazo I > Sulfonazo III. There are two very interesting aspects to the phase transfer of colloidal Pu(IV) that become apparent in examining the extraction data in Tables 6 and 7. In the first case, Sulfonazo III actually depresses the partitioning of colloidal Pu(IV) relative to the same system in the absence of any complexants. The reason for this is not clear, but it is unlikely that Sulfonazo III even binds to the colloid surface. The second aspect refers to the structure of the complexants and their function as phase transfer agents. All three complexants in Table 7 contain hydrophilic functional groups distributed on all sides of the molecule. Attachment to a particle surface would not be expected to impart significant hydrophobicity to the solid/liquid interface, unlike phase transfer agents such as olelc acid that were discussed earlier, where an extensive hydrocarbon moiety renders the solid hydrophobic following attachment of the functional group to the surface.

The extraction of colloidal Pu(IV) by Arsenazo III as a function of $\mathrm{pH}$ is shown in Fig. 17. As the $\mathrm{pH}$ is increased from 2 to 3.5, the partition coefncient of $\mathrm{Pu}$ increases from approximately 0.1 to 500 . The $\mathrm{D}_{\mathrm{Pu}}$ values are essentially independent of $\mathrm{pH}$ between 3.5 and 9 . This pH dependency would allow efficient extraction of plutonium at neutral to alkaline $\mathrm{pHs}$ and then back extraction at a slightly acidic $\mathrm{pH}$.

As the mass balance data in Table 8 indicate, very good $P u$ recoveries are obtained along with the good extraction capabilities of the aqueous biphase system. In conventional oll/water solvent extraction systems, poor $\mathrm{Pu}$ mass balances and interfacial crud formation are serious problems [MUSCATELLO, OCKENDEN, THIYAGARAJAN]. In Table 8 , the bulk phase recovery refers to the percentage of total alpha counts added to the biphase system that were recovered in the bulk liquid phases. The Pu mass balance refers to the percentage of alpha counts that were recovered from the bulk liquid phases and the liquid/liquid interface.

The procedure for measuring the mass balance involved separating the equilibrated aqueous phases, removing portions of each phase, and placing them in separate vials for sampling. The remaining interphase region was then transferred to a new vial. The bulk phase samples were then combined with the interphase sample; $2 \mathrm{~mL}$ of distilled water was first used to rinse the original vials, then was added to produce a single liquid phase. The total alpha counts present in the combined sample were then determined. 
Table 8. Plutonium Bulk Phase Recovery and Mass Balance during Extraction In the $15 \%\left(\mathrm{NH}_{4}\right)_{2} \mathrm{SO}_{4} / 15 \%$ PEG-3400 Blphase System at $25^{\circ} \mathrm{C}$

\begin{tabular}{lccc}
\hline $\begin{array}{l}\text { [Arsenazo III]. } \\
\text { wt \% }\end{array}$ & DPu & $\begin{array}{c}\text { Bulk Phase Pu } \\
\text { Recovery, \% }\end{array}$ & $\begin{array}{c}\text { Pu Mass Balance, } \\
\%\end{array}$ \\
\hline 0.0015 & 202 & 86.0 & 91.0 \\
0.0025 & 194 & 89.7 & 91.0 \\
0.005 & 337 & 92.2 & 92.4 \\
0.0075 & 446 & 92.2 & 92.8 \\
0.010 & 457 & 93.2 & 95.5 \\
0.015 & 525 & 92.2 & 91.3 \\
\hline
\end{tabular}

Plutonium recoveries in Table 8 refer to the data plotted in Fig. 16 and range from 86 to $93 \%$. Comparing these numbers with the mass balance values indicate very little loss of Pu to liquid/liquid interfacial adsorption. However, approximately 8 to $9 \%$ of the total Pu added to the biphase system was lost due to adsorption onto the glass vial surface.

While Arsenazo III is an effective phase transfer agent capable of achieving high bulk phase recoveries of $\mathrm{Pu}$, it is fairly toxic and therefore presents a serious waste management problem. Clearly, other phase transfer agents are needed. A number of surfactants and metal complexants were screened for potential use as Pu PTAs. The extraction data obtained at PTA concentrations of 0.01 and $0.1 \mathrm{wt} \%$ are presented in Tables 9 and 10 . The $\%$ recovery refers to $\mathrm{Pu}$ recovery in the bulk liquid phases. Values less than $100 \%$ indicate that $\mathrm{Pu}$ was lost to adsorption at either the liquid/liquid or solid/liquid interfaces. In every case, the DPu values were less than 1 , except for the system containing $0.01 \%$ humic acid, where the $\mathrm{DPu}$ value was 2.2. The extraction of polymeric $\mathrm{Pu}(\mathrm{IV})$ by humic acid indicates that it is capable of complexing the $\mathrm{Pu}$ polymer. This result agrees with studies of natural water systems, in which plutonium has been strongly associated with colloidal organic compounds [NELSON].

As discussed earlier, highly water soluble PTAs tend to be ineffective in high Ionic strength biphase systems unless there is a very specific, highly energetic Interaction between the PTA and the solid surface. This is probably the reason why none of the PTAs in Tables 9 and 10 worked very well. They are all quite soluble in water and aqueous electrolyte solutions. Complexants of a more limited water solubility, such as oleic acid, will be surveyed next.

Another separation strategy that we will be evaluating involves the use of a starch or other appropriate compound as a depressant that would be permitted to adsorb to metal oxide surfaces. Selective adsorption would be achieved by controlling the particle surface charge through pH adjustment. Once the targeted species are 
surface-modiffed, the remaining particulates can be rendered extractable by reaction with sodium silicate. The goal is to effect a separation using reagents that are nontoxic and inexpensive.

Table 9. Partitioning of Polymeric Pu(IV) in the 7.5\% $\mathrm{Na}_{2} \mathrm{SO}_{4} / 15 \%$ PEG-3400 System with $0.01 \%$ PTA Concentration at $25^{\circ} \mathrm{C}$

\begin{tabular}{|c|c|c|}
\hline Phase Transfer Agent & Dpu & $\begin{array}{c}\text { Pu Recovery, } \\
\% \\
\end{array}$ \\
\hline Tween 20 & 0.18 & 0.9 \\
\hline Brij 30 & 0.80 & 0.8 \\
\hline Triton X-100 & 0.47 & 0.5 \\
\hline Humic Acid & 2.2 & 27 \\
\hline $\begin{array}{l}\text { Cetyl Trimethyl } \\
\text { Ammonlum Bromide }\end{array}$ & 0.31 & 0.8 \\
\hline Poly(ethylenimine) & 0.029 & 3 \\
\hline $\begin{array}{l}\text { Naphthalene Disulfonic } \\
\text { Acid }\end{array}$ & 0.0037 & 67 \\
\hline $\begin{array}{l}\text { Naphthalene Trisulfonic } \\
\text { Acid }\end{array}$ & 0.0017 & 74 \\
\hline Sodium Dodecylsulfate & 0.0016 & 98 \\
\hline HEDPa & 0.0045 & 28 \\
\hline Dodecylbenzene Sulfonate & 0.0022 & 52 \\
\hline Aerosol OT & 0.0019 & 61 \\
\hline Oxalic acid & 0.0039 & 38 \\
\hline
\end{tabular}

${ }^{2}$ Chemical formula of HEDP is $\mathrm{CH}_{3} \mathrm{C}(\mathrm{OH})\left[\mathrm{P}(\mathrm{O})(\mathrm{OH})_{2}\right]_{2}$. 
Table 10. Partitioning of Polymeric Pu(IV) in the 7.5\% $\mathrm{Na}_{2} \mathrm{SO}_{4} / 15 \% \mathrm{PEG}-3400$ System with $0.1 \%$ PTA Concentration at $25^{\circ} \mathrm{C}$

\begin{tabular}{|c|c|c|}
\hline Phase Transfer Agent & DPu & $\begin{array}{c}\text { Pu Recovery } \\
\% \\
\end{array}$ \\
\hline Tween 20 & 0.0035 & 59 \\
\hline Brij 30 & 0.01 & 27 \\
\hline Triton X-100 & 0.0047 & 37 \\
\hline Humic Acid & 0.84 & 21 \\
\hline $\begin{array}{l}\text { Cetyl Trimethyl } \\
\text { Ammonium Bromide }\end{array}$ & 0.25 & 4 \\
\hline Poly(ethylenimine) & 0.0071 & 6 \\
\hline $\begin{array}{l}\text { Naphthalene Disulfonic } \\
\text { Acid }\end{array}$ & 0.0019 & 60 \\
\hline $\begin{array}{l}\text { Naphthalene Trisulfonic } \\
\text { Acid }\end{array}$ & 0.0031 & 58 \\
\hline Sodium Dodecylsulfate & 0.0054 & 40 \\
\hline HEDPa & 0.0058 & 96 \\
\hline Dodecylbenzene Sulfonate & 0.0045 & 47 \\
\hline Aerosol OT & 0.0099 & 76 \\
\hline Oxalic actd & 0.0039 & 56 \\
\hline
\end{tabular}

${ }^{\mathrm{a} C h e m i c a l ~ f o r m u l a ~ o f ~} \mathrm{HEDP}$ is $\mathrm{CH}_{3} \mathrm{C}(\mathrm{OH})\left[\mathrm{P}(\mathrm{O})(\mathrm{OH})_{2}\right]_{2}$.

\section{J. Beneflclation of Pu Residues}

Graphite and silica are the major constituents of certain foundry residues and incinerator ash, respectively. Separations of $\mathrm{PuO}_{2}$ /graphite and $\mathrm{PuO}_{2} / \mathrm{SIO}_{2}$ mixtures are therefore of interest and were attempted, using a PEG/sodium sulfate biphase system. In these experiments, polymeric Pu(IV) was used as a stand-in for particulate $\mathrm{PuO}_{2}$. The next series of experiments will be performed using actual Pu-residue samples.

As with other metal oxides, polymeric Pu(IV) partitions quantitatively to the sulfate layer. Its partition coefficient in the PEG-3400/ $\mathrm{Na}_{2} \mathrm{SO}_{4}$ system is approximately 0.001 at pHs from 3 to 6 . During the extraction of polymeric Pu(IV) in the presence of ground amorphous silica, the silica partitioned into the top phase. 
leaving the bottom phase with no trace of cloudiness. The size distribution of the ground silica was between 0.2 and $1.0 \mu \mathrm{m}$, and since the bottom phase was clear, the silica concentration in that phase can be estimated as less than $10^{-4} \mathrm{wt} \%$. Based on the total amount of silica added. slightly greater than $99.99 \%$ of the sllica had partitioned into the top phase. With greater than $99 \%$ of the polymeric Pu(IV) remaining in the bottom phase, a separation factor greater than $10^{6}$ was obtained in a single stage.

Polymeric Pu(IV) is known to be highly surface-active with an ability to adsorb to practically any solid surface [OCKENDEN]. A separation factor of $10^{6}$, therefore, represents a significant separations achievement. In this separation system, the PEG competes with the polymeric Pu(IV) for adsorption sites on the sillica surface. The high separation factors quoted here are obtained when the silica and the Pu polymer are added to the complete biphase system. If the addition of $\mathrm{Pu}$ and $\mathrm{SiO}_{2}$ is made to the salt phase first, followed by addition of the PEG phase, then adsorption of the Pu polymer onto the silica takes place and the separation factors are significantly reduced.

Once the Pu polymer is adsorbed onto the sillca, separation then depends upon the degree to which the Pu can be liberated from the silica. The addition of PEG, by itself, to the system is unable to displace the Pu polymer from the silica surface. To effect a separation, the addition of HF and PEG would be required to liberate the Pu polymer from the silica. In an actual $\mathrm{Pu}$ residue, ultrafine grinding would be used to liberate particulate $\mathrm{PuO}_{2}$ from the host matrix.

The other binary system studied consisted of polymeric Pu(IV)/graphite mixtures. Regardless of $\mathrm{pH}$, the naturally hydrophobic graphite was quantitatively extracted into the PEG phase, leaving no visible trace of color or cloudiness in the bottom sulfate layer. Given a particle size of 1 to $2 \mu \mathrm{m}$, the graphite concentration in the lower phase was estimated to be less than $10^{-4} \mathrm{wt} \%$. The partition coeffictent of the polymerized $\mathrm{Pu}(\mathrm{IV})$ was 4 in this case. This large partition coefficient for plutonium is probably due to adsorption of the Pu polymer onto the graphite particles. Since the graphite is hydrophobic, PEG interacts primarily through relatively weak dispersion forces. The fact that the hydrous Pu polymer is so strongly adsorbed onto the graphite is a surprise, especially since the Pu polymer appears to adsorb onto graphite better than it does onto humic acid, which contains a wide array of metal chelating groups.

Table 11. Partitioning of Colloldal $\mathrm{PuO}_{2}$ in Binary Particulate Systems ${ }^{\mathrm{a}}$

\begin{tabular}{llccc}
\hline \multirow{2}{*}{ System } & Reagent & \multicolumn{3}{c}{ Partition Coefficient } \\
\cline { 3 - 5 } & & $\mathrm{PuO}_{2}$ & $\mathrm{SiO}_{2}$ & Graphite \\
\hline $\mathrm{PuO}_{2} / \mathrm{SiO}_{2}$ & None & 0.009 & $>10^{4}$ & \\
$\mathrm{PuO}_{2} /$ Graphite & None & 4.0 & & $>10^{3}$ \\
$\mathrm{PuO}_{2} /$ Graphite & $0.01 \%$ AOT & 0.04 & & $>10^{3}$ \\
\hline
\end{tabular}

aAqueous biphase system: $15 \%$ PEG-3400/7.5\% sodium sulfate at $\mathrm{pH} 3$.

bAOT: sodium bis(2-ethylhexyl)sulfosuccinate, Aerosol OT. 
By adding $100 \mathrm{ppm}$ Aerosol OT to the biphase system. the partition coefficient of plutonium was reduced to 0.04 . It is possible that the partition coefficient could be reduced even further by optimlzing the cholce of dispersing agent and its concentration. Interestingly, the Aerosol OT was effective only when it was added as a dodecane solution. Using an aqueous Aerosol OT stock solution actually resulted in Pu partition coefficients larger than 4. It is possible that adsorption of the hydrocarbon, alone, at the graphite surface is responsible for blocking Pu polymer adsorption. In fact, when $100 \mathrm{ppm}$ dodecane is added to the aqueous biphase system, the partition coefficient of plutonium drops to 0.02 . However, in the absence of Aerosol OT, the dodecane also caused the graphite to agglomerate and then partition to the top phase. At the same time, the larger graphite agglomerates settled to the bottom of the test tube; otherwise. the bottom, sulfate phase remained clear as before. Surface modification of activated and graphitic carbons with additives such as kerosene is commonly used in gold beneficiation as a means of reducing gold adsorption in carbonaceous ores [OSSEOASARE]. The mechanism by which organic compounds inhibit gold uptake by the carbonaceous material is not fully understood, but it is believed to involve both hydrophobic and electrostatic interactions [OSSEO-ASARE].

Aging of polymeric Pu(IV) at high temperatures or for extended perlods of time at room temperature leads to an increased resistance toward depolymerization. The aging process is believed to involve the loss of water from adjacent hydroxo bridges, leading to the irreversible formation of Pu-O-Pu bonds [SEABORG, GIMBLETT]. Plutonium linkage through hydroxo bridges would be expected to lead to hydrophilic surface sites capable of taking part in the same types of hydrogen bond complexation reactions as silanol groups on the silica surface. With aging, the appearance of oxo bridges in the $\mathrm{Pu}$ polymer apparently leads to the generation of surface sites having physico-chemical properties that are in some ways simllar to the hydrophobic siloxane surface. A combination of hydrophilic and hydrophobic surface sites on the $\mathrm{Pu}$ polymer would explain its pronounced tendency to adsorb at the oil/water interface and its ability to cause excessive foaming during evaporation operations [CLEVELAND-1967]. It would also explain the ability to adsorb onto graphite.

Clearly, further study is needed to fully understand the colloidal properties of Pu(IV). Such studies would not only assist the development of better separation processes, but would also assist the understanding of actinide interactions with and transport through environmental systems.

\section{SUMMARY AND CONCLUSIONS}

This report presents a summary of experiments carried out during the first year of a three-year project to develop aqueous biphasic extraction systems for separating and recovering radioactive or hazardous constituents from aqueous waste streams or solid residues. This project will culminate with a laboratory proof-of-concept demonstration of a continuous, aqueous biphasic separation using a plutonium residue as a feed material. 
Aqueous biphasic extraction offers the potential for obtaining extremely high separation factors between metal oxides, silicates, and aluminosilicates. The ability of this separation technique to separate particles that are $\leq 1 \mu \mathrm{m}$ makes it feasible to use ultrafine grinding to liberate $\mathrm{PuO}_{2}$ from plutonium-containing residues. This technology could also have applications in the radioactive decontamination of the fine clay portion of soils. For aqueous biphasic extraction to be economically viable for soll remediation, the contaminants must be in a state of liberation from the soll particles and therefore not require preparation by ultrafine grinding.

Initial grinding studies were carried out with a vibratory mill and have shown that products with an average particle stze of $1 \mu \mathrm{m}$ or less can be produced with grinding times of 2 to $15 \mathrm{~h}$, depending on the hardness of the materfal being ground. One of the harder materials ground was high-fired $\mathrm{UO}_{2}$, which required $15 \mathrm{~h}$ to reach the micron size range. Commercial-scale collold mills are avallable with maximum pulp feed capacities of 3 to 10 gal. A single mill should produce about $4000 \mathrm{~kg}$ of $<1 \mu \mathrm{m}$ material per year, even with grinding times of $15 \mathrm{~h}$. Given the relatively low volume of Puresidue materials, grinding to an average stze of $1 \mu \mathrm{m}$ should not be difficult.

Phase diagram data are needed to design an aqueous biphasic solvent extraction process. Phase diagrams of a number of these systems are avallable in the literature; usually, however, they are primarily applicable to biological separations. We have measured phase diagrams for the sodium sulfate/polyethylene glycol system using a radiotracer technique that significantly reduces the data acquisition time. Phase diagrams for the carbonate, nitrate/polymer systems will be measured in the comming year.

Studies of the interfacial and colloidal properties of polymeric Pu(IV) were also initiated to examine the partitioning behavior of hydrous metal polymers in aqueous biphasic extraction systems. Polymeric Pu(IV) is also being used as a stand-in for partitioning studies of ground $\mathrm{PuO}_{2}$. The appropriateness of using polymeric $\mathrm{Pu}(\mathrm{IV})$ as a model for ground $\mathrm{PuO}_{2}$ will be evaluated from extraction measurements of monomeric $\mathrm{Pu}(\mathrm{IV})$, polymeric $\mathrm{Pu}(\mathrm{IV})$, and ground $\mathrm{PuO}_{2}$. The interfacial and colloidal properties of polymeric $\mathrm{Pu}(\mathrm{IV})$ are being studied by interfacial adsorption measurements and dynamic laser light scattering measurements. The surface properties of particulate $\mathrm{PuO}_{2}$ will be studied by zeta potential measurements.

The adsorption studies of polymeric Pu(IV) have shown that the colloidal species are not in equilibrium with one another and that two classes of species exist: those that are interfacially active and those that are not. The appearance of $\mathrm{Pu}-\mathrm{OH}$ and $\mathrm{Pu}-\mathrm{O}-\mathrm{Pu}$ surface sites on the same polymer molecule is probably the source of its interfacial activity. The surfactant Aerosol OT was found to completely inhibit the adsorption of polymeric Pu(IV) at the solid/liquid interface. On the other hand, complexants like dextran increased the interfacial adsorption. Attempts to correlate interfacial activity with particle-size distribution have been unsuccessful because of difficulties in making reliable light scattering measurements. Part of the problem is probably due to sample contamination with dust, which we can eliminate by modifying our sample preparation techniques. The inherent instability of polymeric Pu(IV) solutions also makes it difficult to measure size distributions. The judicious use of surfactants like 
Aerosol oT may stabllize the particles long enough to make the light scattering measurements.

A number of complexants and surfactants were examined for their ability to extract polymeric Pu(IV) in the sodium sulfate/polyethylene glycol system. The only reagents to produce $\mathrm{DPu}_{\mathrm{Pu}}$ values greater than 1 were Arsenazo I, Arsenazo III, and humic acid, which gave maximum values of 2,600 , and 2, respectively. In preliminary tests with model systems containing polymeric Pu(IV), single-stage separation factors of $10^{4}$ to $10^{6}$ were obtained with $\mathrm{Pu} / \mathrm{graphite}$ and $\mathrm{Pu} / \mathrm{SiO}_{2}$ mixtures, respectively. The fact that such high separation factors were obtained with highly surface active polymeric Pu(IV) represents a significant separations achievement. We will continue to evaluate metal complexants for potential application as PTAs in aqueous biphasic extraction systems. Our goal is to identify PTAs that are nontoxic, inexpensive, and biodegradable.

Studies focusing on the separation of particulate $\mathrm{PuO}_{2}$ from other metal oxides and $\mathrm{SiO}_{2}$ will be carried out using actual Pu residues. Wet grinding studies will be expanded to evaluate the extent of plutonium liberation during particle-size reduction. The results of this liberation study will be published as a separate topical report in FY93. Process flowsheet development will be initiated while extraction chemistry studies continue to be performed. Key issues include the recycle of reagents and aqueous process streams, recovery of particulates from the salt and polymer phases, and choice of contactor equipment.

\section{PLANS FOR THE NEXT YEAR}

The wet grinding studies that were discussed above will be expanded to evaluate the extent of plutonium liberation during particle-size reduction of plutonium residues. We hope to include ash, ash heels, sand, slag \& crucibles, and plutonium-contaminated LECO crucibles in these liberation studies. The plutonium residues will be characterized by scanning electron microscopy/x-ray energy-dispersive spectroscopy (EDS) to determine particle morphology and elemental composition. Individual plutonium containing particles will be isolated, mounted, and thin-sectioned for analytical transmission electron microscopy. We hope to identify the chemical composition of plutonium-containing phases by electron diffraction measurements from thin-sectioned specimens. The results of the grinding/liberation studies will be published as a separate topical report in FY92.

We will continue to evaluate metal complexants for potential use as PTAs in aqueous biphasic extraction systems. The goal is to identify PTAs that are selective for $\mathrm{Pu}$ and are nontoxic, inexpensive, and blodegradable. The success of oleic acid as a PTA suggests that a high water solubility is not a prerequisite for successful PTAs. Other sparingly-soluble reagents, such as tributyl phosphate, will be examined as potential PTAs for selective recovery of $\mathrm{PuO}_{2}$.

Laser light scattering studies will be expanded to include an investigation of critical behavior of PEG/salt solutions by dynamic and static scattering 
measurements. The intention of these studies is to elucidate the mechanism by which certain inorganic salts influence the cloud point of high molecular weight PEGs. Specifically, we would like to examine the effect of these salts on the conformational ordering of the PEG chain in aqueous solutions and to determine whether or not disordered/ordered transitions lead to phase separation.

Partitioning studies focusing on the separation of particulate $\mathrm{PuO}_{2}$ from other metal oxides and silicates will be carried out using actual Pu residues. In addition, we will carry out a series of extractions using various PTAs such as Arsenazo III in order to correlate the partition behaviors of monomeric Pu(IV), polymeric Pu(IV), and subinicron, particulate $\mathrm{PuO}_{2}$. At the same time, process flowsheet development will be Initlated. Key issues include recycling reagents and aqueous process streams, recovering particulates from the salt and polymer phases, and selecting contactor equipment. The measurement of phase diagrams will continue with an emphasis on carbonate/PEG systems. This salt/polymer system would have a minimal environmental impact, making it particularly suited to soil remediation applications. 


\section{ACKNOWLEDGMENTS}

Funding for this work is being provided by the Basic Energy Sclences Program. Division of Advanced Energy Projects, Department of Energy. Dr. Walter M. Polansky. Director.

The authors would like to thank Dr. Lary Avens of Los Alamos National Laboratory and Dr. Mel Coops of Lawrence Livermore National Laboratory: Dr. Dean Pierce and Herb Diamond of Argonne National Laboratory for providing samples of $\mathrm{Pu}$ residues and Pu polymer solutions and Dr. Jess Wilcoxon of Sandia National Laboratory for helpful discussions on light scattering techniques. 


\section{REFERENCES}

\section{ALBERTSSON}

P.-A. Albertsson. Partition of Cell Particles and Macromolecules, 3rd ed., Wiley-Interscience, New York (1986).

ANANTHAPADMANABHAN-1987A

K. P. Ananthapadmanabhan and E. D. Goddard, "Process for the Separation of Solid Particulate Matter," U. S. Patent 47,225,358 (1987).

ANANTHAPADMANABHAN - 1987B

K. P. Ananthapadmanabhan and E. D. Goddard, Langmuir 3 , 25 (1987).

AVENS

L. R. Avens, U. F. Gallegos, and J. T. McFarlan, Sep. Sci. Technol. 25, 1967 (1990).

\section{BAMBERGER}

S. Bamberger et al., J. Colloid Interface Sci. 99, 194 (1984).

BOLT

G. H. Bolt, M. F. DeBoodt, M. H. B. Hayes, and M. B. McBride. Interactions at the Soll Colloid-Soll Solution Interface, Kluwer Academic Pub., Boston. p. 22 (1991).

BROWN

G. Brown, A. C. D. Newman, J. H. Rayner, and A H. Weir, "The Structures and Chemistry of Soil Clay Minerals, in The Chemistry of Soll Constituents, D. J. Greenland and M. H. B. Hayes, Eds., John Wiley \& Sons, New York, pp. 29178 (1978).

CARNIGLIA

S. C. Carniglia in Chemistry of Plutonium. Metallurgical Project Report CN-2330 (1944).

CHAIKO-1989

D. J. Chalko, L. Reichley-Yinger, E. R. Orth, E. H. Van Deventer,

G. F. Vandegrift, M. Krumpolc, J. E. Helt, R. D. Coleman, S. N. Kakar,

T. S. Tsal, K. Horken, W. Killian, and N. F. Sather, "Development of a Process for Treating Red Water by Organic/Inorganic Separation and Blodegradation." in Proceedings 14th Annual Army Environmental R\&D Symposium. USATHAMA Report CETHA-TE-TR-90055, p. 303 (1989).

CHAIKO-1991A

D. J. Chaiko, Argonne National Laboratory, unpublished information (1991).

CHAIKO-1991B

D. J. Chalko, "Aqueous Biphase Process for Actinide Recovery From Solld Wastes," in Chemical Technology Division Annual Technical Report. ANL-91/18, p. 103 (May 1991).

CHAIKO-1992

D. J. Chaiko, Sep. Sci. Technol. 27. 1389 (1992).

\section{CHRISTENSEN}

D. C. Christensen, D. F. Bowersox, B. J. McKerley, and R L. Nance, Waste from Plutonlum Conversion and Scrap Recovery Operations, U. S. DOE Report LA-1 1-69-MS (1988). 
$\mathrm{CHU}$

B. Chu, Laser Light Scattering, 2nd ed., Academic Press, San Dlego, pp. 51 and 252 (1991).

CLEVELAND- 1967

J. M. Cleveland, "Solution Chemistry of Plutonium, " in Plutonium Handbook,

Vol. 1, Gordon and Breach, New York, Chapter 13 (1967).

CLEVELAND-1979

J. M. Cleveland, The Chemistry of Plutonlum, American Nuclear Society, La Grange Park, IL, p.86 (1979).

DIAMOND

H. Diamond, Chemistry Division, Argonne National Laboratory, personal communication (1990).

ELWORTHY

P. H. Elworthy, A. T. Florence, and C. B. Macfarlane, Solubilization by Surface-Active Agents. Chapman and Hall Ltd., London (1968).

FORD

N. C. Ford, Jr., "Light Scattering Apparatus" in Dynamic Light Scattering,

R Pecora, Ed., Plenum Press, New York, pp.49-50 (1985).

FUERSTENAU-1962

D. W. Fuerstenau, Ed., Froth Flotation, 50th Anniversary Volume, AIME, New York (1962).

FUERSTENAU-1970

D. W. Fuerstenau, Pure Appl. Chem. 24. 135 (1970).

FUERSTENAU-1976

D. W. Fuerstenau and S. Roghaven, in Flotation, M. C. Fuerstenau, Ed., AIME, New York, p. 33 (1976).

GAIGALAS

A K. Gaigalas, J. B. Hubbard, M. McCurley, and S. Woo, J. Phys. Chem, 96. 2355 (1992).

GIMBLETT

F. G. R. Gimblett. Inorganic Polymer Chemistry, Butterworths, London, p. 80 (1963).

GREENLAND

D. J. Greenland and C. J. B. Mott, "Surfaces of Soll Particles," in The Chemistry of Soil Constituents, D. J. Greenland and M. H. B. Hayes, Eds., John Wiley \& Sons, New York, p. 331 (1978).

GULLICKSON

N. D. Gullickson, J. F. Scamehorn, and J. H. Harwell, in Surfactant-Based. Separation Processes, J. F. Scamehorn and J. H. Horwell, Eds., Surfactant Science Series Vol. 33, Marcel Dekker, New York, p. 305 (1989).

HOEGLER

J. M. Hoegler and W. M. Bradshaw, Magnetic Separation of Department of

Energy Wastes, U. S. DOE Report ORNL -TM-11117 (1989). 
HOYER-1987

J. L. Hoyer, Effects of Turbomilling Parameters on the Comminution of a-SiC,

U. S. Bureau of Mines Report RI 9097 (1987).

HOYER-1988

J. L. Hoyer, Ceramic Bull. 67, 1663 (1988).

HUSTEDT

H. Hustedt, K. H. Kroner, and M.-R. Kula, in Partitioning in Aqueous Two-

Phase Systems, Academic Press, New York, p. 529 (1985).

ILER-1979A

R. K. Iler, The Chemistry of Sllica, John Wiley, New York, Ch. 3 (1979).

ILER-1979B

R. K. Iler, The Chemistry of Sllica, John Wiley, New York, Ch. 4 (1979).

ILER-1979C

R. K. Iler, The Chemistry of Silica, John Wiley, New York, p. 10 (1979).

KOPPEL

D. E. Koppel, J. Chem. Phys. 57, 4814 (1972).

KULA

M.-R. Kula, in Enzyme Technology, Applied Biochemistry and Bioengineering, Vol. 2, L. B. Wingard, Jr., E. Katchalski-Katzier, and L. Goldstein, Eds., Academic Press, New York, p. 74 (1979).

LEHNINGER

A. L. Lehninger, Biochemistry, 2nd ed., Worth Publishers, New York, pp. 264266 (1975).

LEJA

J. Leja, Surface Chemistry of Froth Flotation. Plenum Press, New York (1982).

LINDQVIST

I. Lindqvist, Swedish J. Agric. Res. 14, 171 (1984).

LIU

8. Liu and J. S. Laskowskd, J. Colloid Interface Sci. 130, 101 (1989).

MARGOLIASH

E. Margoliash, and J. Lustgarten, J. Biol. Chem. 237, 3397 (1962).

MOLOCHNIKOVA-1987

N. P. Molochnikova, V. Ya. Frenkel, B. F. Myasoedov, V. M. Shkinev,

B. Ya. Splvakov, and Yu. A. Zolotov, Radiokhimtya 29, 39 (1987).

MOLOCHNIKOVA-1988A

N. P. Molochntkova, V. Ya. Frenkel, and B. F. Myasoedov, J. Radioanalytical Nucl. Chem. 121, 409 (1988).

MOLOCHNIKOVA-1988B

N. P. Molochnikova, V. M. Shkinev, B. Ya. Splvakov, Yu. A. Zolotov, and

B. F. Myasoedov, Radiokhimlya $\underline{30}, 60$ (1988). 
MUK

A. A. Muk and S. B. Savvin, Zh. Anal. Khim. 26, 98 (1971).

MUSCATELLO

A. C. Muscatello, J. D. Navratil, and M. E. Killion, Sep. Sci. Technol. 18, 1731 NICOLI (1983).

D. F. Nicoll, D. C. McKenzie, and J. -S. Wu, American Laboratory 40, 33 (1991).

OCKENDEN

D. W. Ockenden and G. A. Welch, J. Chem. Soc. 3358 (1956).

OSSEO-ASARE

K. Osseo-Asare, P. M. Afenya, and G. M. K. Abotsi, "Carbonaceous Matter in Gold Ores: Isolation. Characterixation and Adsorption Behavior in

Aurocyanide Solutions, " in Precious Metals:Mining. Extraction. and

Processing, V. Kudryk. D. A Corrigan, and W. W. Llang. TMS, Warrenville,

PA, p. 1265 (1984).

PHILLIES

G. D. J. Phillies, Anal. Chem. 62, 1049A (1990).

PILENI

M. P. Pileni, Ed., Structure and Reactivity in Reverse Micelles. Elsevier, New York (1989).

RAJ

T. Raj and W. H. Flygare, Biochemistry, 13, 3336 (1974).

RAUSELL-COLOM

J. A. Rausell-Colom and J. M. Serratosa, "Reactions of Clays with Organic Substances," in Chemistry of Clays and Clay Minerals, A. C. D. Newman, Ed., Wiley-Interscience, New York, p. 395 (1990).

ROSEN-1989A

M. J. Rosen, Surfactants and Interfacial Phenomena, 2nd ed., John Wiley \&

Sons, New York, p. 13 (1989).

ROSEN-1989B

M. J. Rosen, Surfactants and Interfacial Phenomena, 2nd ed., John Wiley \&

Sons, New York, p.41 (1989).

RYDEN

J. Ryden and P.-A. Albertsson, J. Colloid Interface ScI. 37, 219 (1971).

SAVVIN

S. B. Savvin, Talanta 8. 673, (1961).

SCHUERCH

S. Schuerch, D. F. Gerson, and D. J. L. Mclver, Blochim. Blophys. Acta 640 , 557 (1981).

SEABORG

G. T. Seaborg and W. D. Loveland. The Elements Beyond Uranium. John Wiley \& Sons, New York, p. 90 (1990). 


\section{SHKINEV}

V. M. Shkinev, N. P. Molochnikova, T. I. Zvarova, B. Ya. Splvakov,

B. F. Myasoedov, and Yu. A. Zolotov, J. Radioanal. Nucl. Chem. 88, 115 (1985).

\section{SHUGAR}

G. J. Shugar, R. A. Shugar, L. Bauman, and R . S. Bauman, Chemical

Technicians' Ready Reference Handbook, 2nd ed., McGraw-Hill, New York, p. 63 (1981).

STANCZYK

M. H. Stanczyk and I. L. Feld, Comminution by the Attrition Grinding Process,

U. S. Bureau of Mines Rept. No. B 670 (1980).

STOCK

R. S. Stock and W. H. Ray. J. Polymer Scl.: Polym. Phys. Ed. 23, 1393 (1985).

TAYLOR

R. M. Taylor, "Non-Silicate Oxides and Hydroxides," in Chemistry of Clays and Clay Minerals, A. C. D. Newman, Ed., Wiley-Interscience, New York, p. 395 (1990).

THIYAGARAJAN

P. Thlyagarajan, H. Diamond, L. Soderholm, E. P. Horwitz, L. M. Toth, and

L. K. Felker, Inorg. Chem. 29, 1902 (1990).

TREWHELLA-1988

J. Trewhella, V. A. P. Carlson, E. H. Curtis, and D. B. Heidorn, Blochemistry 27. 1121 (1988) .

VAN DE SANDE

W. Van De Sande and A. Persoons, J. Phys. Chem. 89, 404 (1985).

WALTER

H. Walter, D. E. Brooks, and D. Fisher, Eds., Partitioning in Aqueous Two-

Phase Systems, Academic Press, New York (1985).

WICHNER

R. P. Wichner, A. A. Khan, and J. M. Hoegler, Separation of Depleted Uranium Fragments from Gun Test Catchments, U. S. DOE Report ORNL-TM-11141 (1989).

WILCOXON

J. P. Wilcoxon, Sandia National Laboratory, personnal communication (1991).

WITTMER

D. E. Wittmer, Use of Bureau of Mines Turbomill to Produce High-Purlty Ultrafine Nonoxide Ceramic Powders, U. S. Bureau of Mines Report RI 8854 (1984).

ZVAROVA

T. I. Zvarova, V. M. Shkinev, G. A. Vorob'eva, B. Ya. Spivakov, and Yu. A. Zolotov, Mikrochim. Acta 3, 449 (1984). 


\section{APPENDIX. \\ LIGUID SCINTILLATION COUNTING}

Some partitioning data for plutonium were measured in which Arsenazo III was employed as the phase transfer agent. The partition coefficients of ${ }^{238.239} \mathrm{Pu}$ species in aqueous biphase systems were determined by counting the alpha activity in appropriate aliquot sizes from both liquid phases with a liquid scintillation counter (Packard TriCarb). Because the solutions containing Arsenazo III are strongly colored, even at Arsenazo III concentrations of $0.01 \%$, a series of measurements were performed in order to determine the extent, if any, of color quenching. Varrying amounts of Arsenazo III were added to separate vials containing $20 \mathrm{~mL}$ of scintillation cocktall and equal amounts of either monomeric ${ }^{238} \mathrm{Pu}$ or polymeric ${ }^{239} \mathrm{Pu}$. The plutonium was added by splking the scintillation cocktall with $3 \mu \mathrm{L}$ of the appropriate plutonium stock solution. As shown in Table A-1, the addition of Arsenazo III to the scintillation cocktall had no effect on the counting efficiency of either monomeric or polymeric plutonium(IV). The Arsenazo III was added to the scintlllation cocktall as a 1 wt $\%$ solution of varying volumes. The average counts measured for $\mathrm{Pu}$ polymer and monomer were $547,089 \pm 6.774$ and $610,706 \pm 6,703$, respectively.

The effect of $\left(\mathrm{NH}_{4}\right)_{2} \mathrm{SO}_{4}$ on Pu(IV) counting efficiency was also measured. Because of the high lonic strength of the aqueous biphase systems, we were concerned that the salts might lead to phase separation in the scintillation cocktail and thereby lead to reduced counting effeciencies. We used the same procedure described above except that in place of Arsenazo III, varying amounts of ammonium sulfate were added. The stock salt solution contained $15 \mathrm{wt} \%\left(\mathrm{NH}_{4}\right)_{2} \mathrm{SO}_{4}$ in water. The counting data are presented in Table A-2. The average counts measured for Pu polymer and monomer were $549,757 \pm 6.922$ and $611,175 \pm 5,159$, respectively.

No detectable trend in counting efficlency was observed in any of the conditions examined. The random variation in the count rate that was observed ranged from 2.0 to $2.8 \%$. It is attributed to errors in pipetting the $3-\mu \mathrm{L}$ aliquots of Pu stock solutions into the scintillation cocktail.

Table 12. Effect of Arsenazo III on Plutonium Scintillation Counting

\begin{tabular}{ccc}
\hline & \multicolumn{2}{c}{ Counts per Min (0-2000 keV) } \\
\cline { 2 - 3 } $\begin{array}{c}\text { Volume of Arsenazo III, } \\
\mu \mathrm{L}\end{array}$ & Polymeric Pu(IV) & Monomeric Pu(IV) \\
\hline & & \\
10 & 543,167 & 605,583 \\
20 & 556,980 & 604,951 \\
50 & 542,280 & 618,995 \\
70 & 545,930 & 613,296 \\
\hline
\end{tabular}


Table 13. Effect of $\left(\mathrm{NH}_{4}\right)_{2} \mathrm{SO}_{4}$ on Plutonium Scintillation Counting

\begin{tabular}{ccc}
\hline & \multicolumn{2}{c}{ Counts per Min $(0-2000 \mathrm{keV})$} \\
\cline { 2 - 3 } $\begin{array}{c}\text { Volume of }\left(\mathrm{NH}_{4}\right)_{2} \mathrm{SO}_{4}, \\
\end{array}$ & Polymeric Pu(IV) & Monomeric Pu(IV) \\
\hline 10 & 539,539 & 604,165 \\
20 & 551,510 & 611,885 \\
50 & 553,502 & 616,602 \\
70 & 554,475 & 612,046 \\
\hline
\end{tabular}


Distribution for ANL-92/36

Internal:

D. L. Barney

J. E. Battles

D. L. Bowers

R. L. Breyne

D. J. Chaiko (10)

J. C. Cunnane

J. E. Harmon
J. E. Helt

T. R. Krause

R. K. Mensah-Biney

C. J. Mertz

K. M. Myles

A. N. Rollins

M. J. Steindler
C. E. Till

G. F. Vandegrift

E. H. Van Deventer

S. Vogler

ANL Patent Dept.

ANL Contract File

TIS Files (3)

External:

DOE-OSTI (2)

ANL Library (2)

Manager, Chicago Operations Office, DOE

J. C. Haugen, DOE-CH

Chemical Technology Division Review Committee Members:

S. Baron, Brookhaven National Laboratory, Upton, NY

D. L. Douglas, Consultant, Bloomington, MN

N. Jarrett, Noel Jarrett Associates, Lower Burrell, PA

J. G. Kay, Drexel University, Philadelphia, PA

J. Stringer, Electric Power Research Institute, Palo Alto, CA

J. B. Wagner, Arizona State University, Tempe, AZ

R. G. Wymer, Consultant, Oak Ridge, TN

M. G. Adamson, Lawrence Livermore National Laboratory, Livermore, CA

L. R. Avens, Los Alamos National Laboratory, Los Alamos, NM

G. S. Barney, Westinghouse Hanford Operations, Richland, WA

C. A. Barrington, Westinghouse Hanford Company, Richland, WA

R. G. Behrens, Los Alamos National Laboratory, Los Alamos, NM

J. T. Bell, Oak Ridge National Laboratory, Oak Ridge, TN

F. W. Benn, U.S. Bureau of Mines, Rolla, MO

J. L. Burnett, USDOE, Office of Basic Energy Sciences, Germantown, MD

G. R. Choppin, Florida State University, Tallahassee, FL

D. C. Christensen, Los Alamos National Laboratory, Los Alamos, NM

R. H. Condit, Lawrence Livermore National Laboratory, Livermore, CA

T. D. Cooper, Westinghouse Hanford Company, Richland, WA

M. S. Coops, Lawrence Livermore National Laboratory, Livermore, CA

J. L. Cox, Pacific Northwest Laboratory, Richland, WA

L. P. Duffy, USDOE, Environmental Restoration \& Waste Management, Washington, DC

L. O. Dworjanyn, Westinghouse Savannah River Company, Aiken, SC

W. R. Dworzak, Los Alamos National Laboratory, Los Alamos, NM 
D. D. Ensor, Tennessee Technological University, Cookeville, TN

C. W. Francis, Oak Ridge National Laboratory, Oak Ridge, TN

J. S. Garfield, Westinghouse Hanford Company, Richland, WA

M. A. Gerber, Pacific Northwest Laboratory, Richland, WA

J. Hyde, USDOE, Office of Technology Development, Washington, DC

D. G. Karraker, Westinghouse Savannah River Company, Aiken, SC

C. M. Kronvall, Westinghouse Hanford Operations, Richland, WA

D. E. Kurath, Pacific Northwest Laboratory, Richland, WA

G. J. Lumetta, Pacific Northwest Laboratory, Richland, WA

J. C. Mailen, Oak Ridge National Laboratory, Oak Ridge, TN

J. S. McCormack, Westinghouse Hanford Company, Richland, WA

C. P. McGinnis, Oak Ridge National Laboratory, Oak Ridge, TN

B. A. Moyer, Oak Ridge National Laboratory, Oak Ridge, TN

A. C. Muscatello, Los Alamos National Laboratory, Los Alamos, NM

K. R. Nuhfer, Westinghouse Materials Company of Ohio, Cincinnati, OH

Office of Basic Energy Sciences, USDOE, Washington, DC

R. M. Orme, Westinghouse Hanford Company, Richland, WA

K. Osseo-Asare, Pennsylvania State University, University Park, PA

M. Palmer, Los Alamos National Laboratory, Los Alamos, NM

W. M. Polansky, USDOE, Office of Basic Energy Sciences, Germantown, MD

R. D. Rogers, Northern Illinois University, DeKalb, IL

B. Salley, Westinghouse Hanford Company, Richland, WA

M. J. Schliebe, Westinghouse Hanford Operations, Richland, WA

T. C. Scott, Oak Ridge National Laboratory, Oak Ridge, TN

B. F. Smith, Los Alamos National Laboratory, Los Alamos, NM

J. L. Swanson, Pacific Northwest Laboratory, Richland, WA

R. Swatzell, Hazardous Waste Remedial Actions Program, Oak Ridge, TN

D. W. Tedder, Georgia Institute of Technology, Atlanta, GA

L. M. Toth, Oak Ridge National Laboratory, Oak Ridge, TN

R. P. Traver, Bergmann USA, Stafford Springs, CT

V. Van Brunt, University of South Carolina, Columbia, SC

R. E. Vandercook, Westinghouse Hanford Company, Richland, WA

J. Watson, Oak Ridge National Laboratory, Oak Ridge, TN

R. M. Wham, Oak Ridge National Laboratory, Oak Ridge, TN

D. E. Wiley, USDOE, Office of Industrial Processes, Washington, DC 
